\title{
Mapeando a área de pensamento social no Brasil: uma análise preliminar de sua produção em artigos
}

\author{
Mapping the research field of social thought in Brazil: a preliminary \\ analysis of its production in articles
}

\section{Mapeando el área del pensamiento social en Brasil: un análisis preliminar de su producción en artículos}

\author{
Lucas Carvalho ${ }^{1, a}$ \\ lucascorreiacarvalho@id.uff.br | http://orcid.org/o00o-0003-0118-7762
}

Antonio Brasil Jr. ${ }^{2, a}$

antoniobrasiljr@gmail.com | http://orcid.org/0000-0001-8653-668X

\footnotetext{
${ }^{1}$ Universidade Federal Fluminense, Instituto de Filosofia e Ciências Humanas. Niterói, RJ, Brasil.

2 Universidade Federal do Rio de Janeiro, Instituto de Filosofia e Ciências Humanas. Rio de Janeiro, RJ, Brasil.

a Doutorado em Sociologia pela Universidade Federal do Rio de Janeiro.
}

\section{RESUMO}

Este artigo busca responder a alguns dos desafios de sistematização, indexação e divulgação de variados documentos acadêmicos da área de pensamento social no Brasil pela Biblioteca Virtual do Pensamento Social (BVPS). Argumentamos que a importância da discussão sobre preservação digital para a BVPS cumpre dois objetivos: o de disponibilizar documentos digitalizados a um público mais amplo e o de mapear a produção contemporânea da área, com intuito de criar uma memória intelectual. Neste artigo, nos deteremos sobretudo no segundo objetivo, tendo em vista definir bem como disponibilizar ao público da biblioteca os critérios de seleção e organização do acervo. Dentro dos limites do recorte proposto, por meio de redes de acoplamento bibliográfico, cocitação e mapas semânticos, apresentaremos aqui uma análise preliminar da produção de artigos na área de pensamento social no Brasil. A atual pesquisa é fundamental para a definição das próximas etapas de ampliação do conteúdo da biblioteca, notadamente a definição de novos seletores de busca, a integração de novos autores e autoras à seção Intérpretes e a indexação de trabalhos com temáticas e abordagens caras à área de pensamento social no Brasil.

Palavras-chave: Pensamento social no Brasil; Preservação digital; Cientometria; Big data; Teoria das citações.

\begin{abstract}
This article seeks to respond to some of the challenges of systematization, indexing and dissemination of various academic documents in the field of social thought in Brazil by the BVPS - Biblioteca Virtual do Pensamento Social (Virtual Library of Social Thought). We argue that the importance of the discussion on digital preservation for the BVPS fulfills two objectives: that of making digitized documents available to a wider audience and that of mapping contemporary production in that field in order to create an intellectual memory. In this article, we will focus mainly on the second objective, in order to define as well as make
\end{abstract}


available to the library public the selection and organization criteria of the collection. Within the limits of the proposed clipping, we will present here a preliminary analysis of the production of articles in the field of social thought in Brazil through networks of bibliographic coupling, co-quotation and semantic maps. The current research is fundamental for the definition of the next steps to expand the content of the library, notably the definition of new search options the integration of new authors in the section Interpreters and the indexing of works containing important themes and approaches for the area of social thought in Brazil.

Keywords: Brazilian social thought; Digital preservation; Scientometrics; Big data; Theory of citation.

\section{RESUMEN}

Este artículo busca responder a algunos de los desafíos de la sistematización, indexación y difusión de diferentes tipos de documentos académicos en el campo del pensamiento social en Brasil por la BVPS - Biblioteca Virtual do Pensamento Social (Biblioteca Virtual del Pensamiento Social). Argumentamos que la importancia de la discusión sobre la preservación digital para la BVPS cumple dos objetivos: el de hacer que los documentos digitalizados estén disponibles para una audiencia más amplia y el de mapear la producción contemporánea en el área para crear una memoria intelectual. En este artículo, nos centraremos principalmente en el segundo objetivo, para definir como también para poner a la disposición del público de la biblioteca los criterios de selección y organización de la colección. Dentro de los límites del recorte propuesto, presentaremos aquí un análisis preliminar de la producción de artículos en el campo del pensamiento social en Brasil a través de redes de acoplamiento bibliográfico, cocitación y mapas semánticos. La investigación actual es fundamental para la definición de los próximos pasos para expandir el contenido de la biblioteca, en particular la definición de nuevos selectores de búsqueda, la integración de nuevos autores y autoras en la sección Intérpretes y la indexación de trabajos conteniendo temas y enfoques relevantes para el área de pensamiento social en Brasil.

Palabras clave: Pensamiento social en Brasil; Preservación digital; Cientometría; Big data; Teoría de la citación.

Este texto compõe o Dossiê Preservação Digital.

Contribuição dos autores:

Concepção e desenho do estudo: ambos os autores.

Aquisição, análise ou interpretação dos dados: ambos os autores.

Redação do manuscrito: ambos os autores.

Revisão crítica do conteúdo intelectual: ambos os autores.

Declaração de conflito de interesses: não há.

Fontes de financiamento: Jovem Cientista do Nosso Estado (JCNE)/ Fundação Carlos Chagas Filho de Amparo à Pesquisa do Estado do Rio de Janeiro (Faperj).

Agradecimentos/Contribuições adicionais: Gostaríamos de agradecer o apoio fundamental da equipe do Instituto de Comunicação e Informação Científica e Tecnológica em Saúde (Icict) da Fiocruz, especialmente Paula Xavier, Luciana Danielle, Adilson Junior, Jaqueline Gomes, Augusto Vinhaes e Claudete Queiroz na criação e na manutenção do site da Biblioteca Virtual do Pensamento Social Brasileiro (BVPS), além do diálogo sobre temas relacionados à cientometria e à biblioteconomia. Agradecimento que se estende a Nísia Trindade Lima e a André Botelho por tornarem a BVPS um espaço de profícuo debate e colaboração intelectual.

Histórico do artigo: submetido: 28 maio 2020 | aceito: 05 ago. 2020 | publicado: 30 set. 2020.

Apresentação anterior: não houve.

Licença CC BY-NC atribuição não comercial. Com essa licença é permitido acessar, baixar (download), copiar, imprimir, compartilhar, reutilizar e distribuir os artigos, desde que para uso não comercial e com a citação da fonte, conferindo os devidos créditos de autoria e menção à Reciis. Nesses casos, nenhuma permissão é necessária por parte dos autores ou dos editores. 


\section{INTRODUÇÃO}

A incorporação de tecnologias de digitalização, preservação e armazenamento de toda sorte de documentos na rotina de pesquisadores e de instituições públicas e privadas parece um processo incontornável na produção do conhecimento nos dias de hoje. Todavia, a discussão sobre os limites e possibilidades empíricos e metodológicos nos usos desses documentos e dessas tecnologias nem sempre tem tido o espaço que merece nas diferentes áreas do conhecimento, à exceção da ciência da informação e da biblioteconomia, cujas contribuições para o tema são fundamentais ${ }^{1}$. No que toca às ciências sociais e de modo geral à área de humanas, a preservação digital de documentos ganha um interesse particular, já que o trabalho em arquivos continua a ser uma de suas principais atividades de pesquisa. Se antes a sistematização e a organização arquivística e documental gerava dados quase sempre de uso restrito aos próprios pesquisadores, agora as formas de preservação digital de documentos potencializam sua disponibilização a um público mais amplo - e não raro esses dados se transformam em um grande volume de metadados, tornando possível sua manipulação para novos fins analíticos. Há aqui uma espécie de cadeia de retroalimentação, na qual a organização da informação gera um novo conjunto de informações sobre um determinado universo de documentos. E tal processo, ao multiplificar as possibilidades de combinação e cruzamento das informações disponíveis, revela-se ele mesmo uma importante fonte de pesquisa ${ }^{2-7}$. Por esse motivo, sociólogos e cientistas sociais em geral, com auxílio de técnicas e discussões da Cientometria e Bibliometria, devem assumir a tarefa de pensar o desafio imposto pela preservação digital, não só de documentos históricos, mas da própria produção contemporânea de suas áreas de pesquisa, da qual são participantes. Compartilhamos da definição de Hedstrom ${ }^{8}$ de que a preservação digital envolve ações de planejamento e a aplicação de métodos e tecnologias de preservação necessários para assegurar que a informação digital de "valor contínuo" permaneça acessível. Valor contínuo, como ressalta a autora, denota o oposto de permanente, o que significa que não há nada de fixo e estabelecido sobre o que e como deve ser preservado, sobretudo quando se trata de formatos digitais.

Portanto, a discussão sobre preservação digital vai além dos cuidados com a integridade dos documentos, abarcando também a sistematização e o uso de registros de metadados ${ }^{9}$. Neste sentido, estamos de acordo com a opinião do crítico literário Franco Moretti - os novos bancos de dados e as ferramentas informacionais disponíveis para analisá-los (a exemplo dos diversos softwares computacionais) permitem criar formas inéditas de observação das próprias ciências sociais, nossa área de interesse, visualizando sua estrutura e dinâmica através don que ele denomina uma leitura distante ${ }^{10,11}$. Modalidades distintas de leitura distante permitiriam, segundo Moretti, uma visão mais ampla e distinta sobre uma área científica, porém nem pior nem melhor do que outras formas de observação como a 'leitura cerrada', mais rente aos textos. Não se trata aqui de retomar velhas polarizações nas ciências humanas entre análises objetivistas e hermenêuticas, como se fossem posições necessariamente opostas. Ao contrário do que estipula certo senso comum, as vantagens de se trabalhar com big data, a exemplo dos metadados da produção científica, não está somente na extensão das informações coletadas, mas no alto nível de detalhe e refinamento delas ${ }^{12}$. Reconhecer isso faz com que o analista tenha que levar a sério as especificidades e as camadas de significados relativamente autônomas a que dão origem esses tipos de dados 5 . Através deles, é possível atingir uma compreensão mais ampla e matizada de diversos campos científicos, além de criar formas mais reflexivas de auto-observação por parte dos pesquisadores, de suas próprias práticas e dos códigos aos quais recorrem ${ }^{13}$.

Um dos projetos que vem atuando e fomentando o debate nas ciências sociais sobre preservação digital, metadados científicos, indexação de documentos e análises cientométricas é a Biblioteca Virtual do Pensamento Social (BVPS), a primeira Biblioteca Virtual de uma área de pesquisa integralmente dedicada 
às ciências humanasi. Inspirada no bem-sucedido exemplo das Bibliotecas Virtuais em Saúde (BVS), que seguem as diretrizes do Centro Latino-Americano e do Caribe de Informação em Ciências da Saúde (Bireme) no sentido de disponibilizar, difundir e democratizar o conhecimento em plataformas de acesso aberto e de fácil operação, a BVPS vem, desde 2015, disponibilizando em seu canal digital um amplo acervo da área de pensamento social no Brasil e na América Latina. De forma genérica, podemos definir a área de pensamento social como aquela dedicada a analisar os chamados "intérpretes" e "interpretações" do Brasilii, reunindo teóricos e pesquisadores das ciências sociais, história, estudos literários, artes em geral e educação ${ }^{16-18}$.

Em razão de seu crescimento nos últimos anos, a área de pensamento social tem feito o esforço de pensar crítica e reflexivamente a sua produção, de modo a reforçar ou criar laços com outras áreas, internas e externas às ciências sociais, assim como o de incorporar novos debates temáticos e metodológicos. Como a criação, manutenção e diversificação de uma área nem sempre é um processo dirigido conscientemente, dependendo em grande medida das redes de relações entre instituições, pesquisadores e pesquisas, o exercício de análise de sua produção contribui não só para formarmos uma visão mais ampla sobre ela, mas também para acompanharmos mudanças, permanências e tendências. Portanto, a 'auto-observação', quer dizer, o esforço de pensar a partir de 'dentro' questões caras a uma determinada área, torna-se um importante elemento, junto a outros, de renovação e diversificação científica, ao fornecer dados e perspectivas que as práticas rotineiras de pesquisa não permitem ${ }^{5,13}$. Além disso, torna-se um aspecto fundamental e constitutivo da própria manutenção do acervo da BVPS, já que ele permite que se mapeie a produção presente na área de pensamento social no Brasil e assim crie uma espécie de memória científica.

Ao lado da facilitação do acesso à produção especializada (artigos científicos, teses e dissertações) e da preservação digital de documentos (papers de eventos, conferências e vídeos, sobretudo), conformando uma espécie de memória da área de pensamento social, a BVPS vem promovendo o diálogo entre técnicas cientométricas e abordagens sociológicas na tentativa de refletir sobre alguns de seus desafios teóricos e empíricos e acerca das possíveis contribuições da área ao campo das ciências sociais e à análise da sociedade brasileira e latino-americana ${ }^{19-21}$. A bem dizer, a BVPS atua na manutenção e expansão de seu acervo e é sobretudo um projeto coletivo de pesquisa. Desde a criação da BVPS, o trabalho de curadoria, seleção e indexação dos documentos foi e permanece o mais desafiador ${ }^{\text {iii. }}$. Isso porque exige da equipe um empenho permanente de atualização da base e de acompanhamento da complexificação semântica da área para a definição dos termos indexadores.

Neste artigo, empreenderemos um esforço preliminar de um mapeamento mais amplo da produção científica da área de pensamento social concentrada no Brasil, com o intuito de subsidiar a difícil tarefa de selecionar os trabalhos a entrarem na base BVPS. Para a primeira etapa da pesquisa em que ele se baseia, optamos por realizar um recorte via algum critério de pertencimento dos pesquisadores à área. Coletamos nomes de 326 pesquisadores que participaram ao menos uma vez nos grupos de trabalho

\footnotetext{
i A coordenação geral da BVPS é da professora Nísia Trindade Lima, atual presidente da Fundação Oswaldo Cruz (Fiocruz), e sua equipe se divide entre um comitê executivo, formado por pesquisadores de diferentes formações e instituições brasileiras, e um comitê executivo, integrado por pesquisadores de referência da área de pensamento social no Brasil e no exterior. A equipe conta, ainda, com uma rede de pesquisadores de diversas instituições brasileiras e estrangeiras, além de uma equipe de técnicos do Instituto de Comunicação e Informação Científica e Tecnológica em Saúde (Icict), uma das unidades da Fiocruz. O site da BVPS é http://bvps.fiocruz.brl. Para divulgação de eventos e publicação de ensaios sobre temáticas variadas ligadas à área de pensamento social, a BVPS conta ainda com um blog https://blogbvps.wordpress.com/.

ii É claro que todo "intérprete" tem uma "interpretação" do Brasil, ou seja, uma compreensão mais ampla da dinâmica e formação da sociedade brasileira. Ainda que possa parecer redundante, recorremos à diferença entre as duas categorias para reforçar o esforço da BVPS e de modo geral da área de pensamento social para recuperar autores e autoras da tradição intelectual brasileira que, embora até pouco tempo não estivessem no cânone de "intérpretes", hoje têm debatidas suas "intepretações" do Brasil ${ }^{14,15}$.

iii Para essa tarefa, coordenada por Antonio Brasil Jr. (PPGSA/UFRJ), contamos com o apoio fundamental da equipe do Instituto de Comunicação e Informação Científica e Tecnológica em Saúde (Icict), especialmente Paula Xavier, Luciana Danielle, Adilson Junior, Jaqueline Gomes, Augusto Vinhaes e Claudete Queiroz.
} 
(GT) de pensamento social dos dois principais congressos das ciências sociais no Brasil, o da Associação Nacional de Pós-Graduação e Pesquisa em Ciências Sociais (Anpocs) e da Sociedade Brasileira de Sociologia (SBS). Com o auxílio do ScriptLattes, software desenvolvido para a extração e compilação automática da produção contidas nos currículos da Plataforma Lattes ${ }^{22}$, coletamos ao todo 7.826 artigos, cujos anos de publicação vão de 1967 a maio de 2019. Nem todos os artigos estão com seus metadados disponíveis, por isso recorremos àqueles indexados na base SciELO Citation Index via plataforma Web of Science, chegando a um novo total de 664 artigos do período de 2002 a maio de 2020. São eles que constituem a amostra das análises que se seguirão. Nem sempre os mecanismos de seleção de documentos das bibliotecas virtuais ou de outras plataformas de armazenamento e preservação documental são explicitados aos leitores. Ainda que esteja no horizonte da BVPS a integração de seus mecanismos de buscas com aqueles das bases indexadores científicas, sobretudo SciELO e Redalyc, é preciso qualificar quais os limites e potencialidades desses mecanismos. O mapeamento aqui proposto, assim acreditamos, cumpre também em grande parte essa função, ao oferecer uma análise interna da coleção de pensamento social contida na base SciELO.

Contudo, antes de continuarmos, gostaríamos de fazer duas observações acerca do recorte realizado: primeiro, o critério de pertencimento a uma área é sempre algo difícil de ser capturado, até mesmo porque talvez seja raro que um pesquisador se identifique exclusivamente com uma especialidade. Isso é particularmente mais difícil na área de pensamento social, com forte interlocução com outras áreas e com reconhecidos trabalhos interdisciplinares. A segunda observação diz respeito à escolha de nos limitarmos à análise dos artigos acadêmicos. Embora o livro ainda seja fundamental para a circulação do conhecimento, sobretudo nas ciências sociais ${ }^{2}$, os artigos vêm ganhando cada vez mais espaço nos currículos dos pesquisadores. Em sentido complementar à análise da produção em livros da área de pensamento social ${ }^{19}$, o intuito deste texto é apontar temas, conceitos e referências que conformam os códigos com os quais operam seus pesquisadores. A vantagem, porém, de tomarmos os artigos como objeto é que eles permitem acompanhar de forma mais dinâmica as discussões de uma área, considerando os tempos distintos de maturação e publicação que, em geral, livros e artigos têm.

$\mathrm{Na}$ primeira parte deste artigo, trabalharemos com as referências citadas nos artigos da amostra selecionada, analisando-os de acordo com alguns métodos cientométricos e de redes para identificarmos comunidades temáticas e pontos de interseção entre o pensamento social e outras especialidades. Na segunda parte, o objetivo é investigar um conjunto de dados (como temas de pesquisa, conceitos recorrentes, autores citados, palavras-chave, entre outros) que permitem mapear a semântica da área de forma a apontar campos de estudo consolidados e mesmo tendências de pesquisa. Em seguida, faremos breves considerações sobre o material levantado e algumas das perspectivas que se abrem para a BVPS daqui em diante.

\section{PENSAMENTO SOCIAL NO BRASIL E SUA PRODUÇÃO EM ARTIGOS}

Como dito anteriormente, a análise cientométrica da produção intelectual da área de pensamento social por meio de seus artigos científicos permite ter acesso aos metadados estruturados de um considerável corpus textual. Metodologicamente, esse material se torna ainda mais valioso porque permite contribuir para o debate central na área de pensamento social no Brasil sobre as relações entre 'texto' e 'contexto'16,21,23. Embora nunca tenha sido algo trivial, a investigação sobre que tipo de relação um 'texto' estabelece com o seu 'contexto' ${ }^{24}$ ganha novas dimensões analíticas a partir das discussões levantadas pela cientometria. Como argumenta Leydesdorff 5 , os metadados da produção científica, tais como os que iremos expor aqui, permitem uma visão dinâmica e ampla da relação entre 'autores', 'textos' e 'cognições'. Cada um desses termos não tem uma definição estável e tampouco podem ser reduzidos uns aos outros, embora mudanças em cada um deles possam ser sentidas nos demais. Para deixar mais claro o ponto, podemos dizer que a 'cognição', isto é, os códigos de comunicação científica (a exemplo das citações), se manifesta 
como conhecimento discursivo na forma de 'textos' (artigos, livros, teses...). Esses códigos de comunicação são socialmente construídos pelas relações estabelecidas por autores e instituições, mas tendem a se transformar em mecanismos relativamente autônomos, eficazes e seletivos no agrupamento entre os textos. Podemos destacar um exemplo do modo como essa perspectiva auxilia na compreensão das dinâmicas científicas que abordaremos em seguida: a rede bibliométrica gerada a partir das relações de coautoria entre pesquisadores em diversos casos é muito distinta da rede baseada nas citações dos trabalhos desses mesmos pesquisadores. Muito provavelmente a rede de coautoria demonstrará relações muito próximas às do contexto institucional dos pesquisadores (em termos de parceria de áreas disciplinares e grupos de pesquisa, por exemplo), ao contrário da rede que toma a similaridade das citações, cujas relações são estabelecidas pelo uso dos códigos de comunicação (autores e obras) compartilhados por pesquisadores de diferentes instituições, grupos de pesquisa e mesmo áreas disciplinares.

Nesse sentido, embora programas de pesquisa e redes de colaboração científica façam parte das práticas cotidianas de pesquisadores - sendo parte importante de estratégias na concorrência por recursos de financiamento e elaboração de projetos, por exemplo -, nem sempre elas podem ser reduzidas a uma dimensão consciente. Ainda que, por vezes, os códigos científicos tendam a criar comunidades científicas muito coesas, chama a atenção que o grau de compartilhamento de referências, citações, autores e temas extrapolem esses nichos e ganhem significados variados e não raro polêmicos no interior de uma especialidade ou área científica. Destacar a independência analítica de cada uma dessas dimensões significa, portanto, conceber a produção científica em sua multidimensionalidade, de modo que melhor possa se responder à questão fundamental de como formas cognitivas emergem entre os autores/agentes, sedimentando-se em 'textos' e conformando um arsenal compartilhado - mas não necessariamente consensual - no interior de uma especialidade disciplinar. Tendo em vista essa discussão, vejamos agora os dados relativos aos artigos da área de pensamento social no Brasil.

Selecionando o período entre 2002 e 2020, encontramos um total de 664 documentos, assim distribuídos temporalmente:

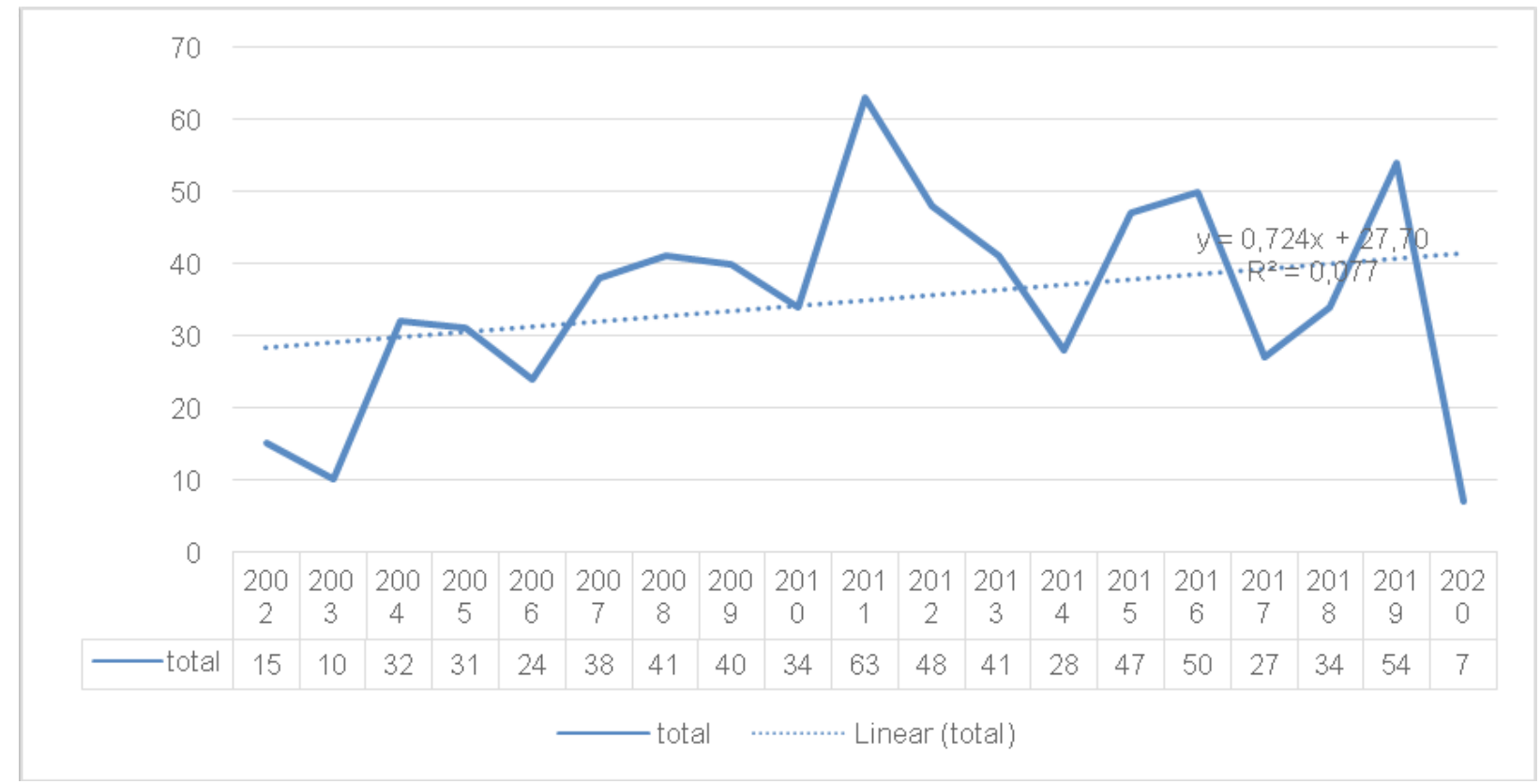

Figura 1 - Artigos dos participantes dos GT de pensamento social no Brasil indexados na base SciELO Citation Index (2002-2020) Fonte: Dados da pesquisa (2020).

Na Figura 1, vemos que a área conta, pelo menos na base SciELO Citation Index, com um volume considerável de produção - desde 2004, quase sempre com mais de 30 documentos por ano, a despeito 
de naturais oscilações. O volume nada desprezível de informações que é possível se extrair desse conjunto de dados pode auxiliar na detecção de temas que permitam indexar a produção intelectual de acordo com os critérios internos e autônomos da área de pesquisa, como, por exemplo, os 'intérpretes do Brasil' mais citados ou as questões mais investigadas. Para tal, procederemos nossa análise utilizando de duas técnicas muito comuns na bibliometria, a saber: o acoplamento bibliográfico de artigos e a cocitação de autores. A primeira permitirá revelar, de acordo com o grau de semelhança entre artigos, medido por meio do compartilhamento de referências bibliográficas, como os documentos se distribuem por diferentes eixos temáticos e/ou disciplinares. Já a segunda permitirá perscrutar quais são os 'intérpretes' mais citados e, ainda mais significativo, como eles se distribuem em termos de suas cocitações, isto é, com quem eles tendem a ser citados juntos mais frequentemente no interior deste corpus.

Antes de seguirmos, vale explicitar melhor como funcionam essas técnicas de análise. $\mathrm{O}$ acoplamento bibliográfico entre dois artigos "ocorre quando estes referenciam pelo menos uma publicação em comum. Nesse contexto, o acoplamento bibliográfico estabelece uma conexão entre dois artigos ao utilizarem as mesmas referências” 25 . Já a cocitação, ao contrário, "identifica a ligação/semelhança de dois documentos citados, via suas frequências de ocorrência conjunta em uma lista de referências dos autores citantes"25. Dito de outro modo, ambas as técnicas procuram identificar proximidades/afastamentos a partir de um compartilhamento maior ou menor de referências bibliográficas. O que muda, fundamentalmente, é a unidade de análise em jogo: na cocitação, a unidade são os autores ou documentos citados, ao passo que, no acoplamento bibliográfico, a unidade são os artigos que citam.

Vamos aos temas, definidos de acordo com o padrão de relações construído por meio do acoplamento bibliográfico. Usando o algoritmo de detecção de comunidades conhecido como Louvain ${ }^{26}$, encontramos 12 comunidades de artigos. Este algoritmo procura distribuir cada elemento da rede em comunidades específicas de acordo com suas relações: quanto maior o peso das relações entre dois elementos, maiores as suas probabilidades de caírem em uma mesma comunidade - calibrando-se, é claro, para o total de relações existentes na rede em questão, no sentido de otimizar a 'modularidade', isto é, a melhor distribuição possível de comunidades para o conjunto dos elementos. Na Figura 2, gerada a partir dos softwares VOSViewer ${ }^{27} \mathrm{e}$ $\mathrm{Gephi}^{28}$, temos a rede de acoplamento dos 546 documentos situados na componente principal da rede - ou seja, aquela que reúne o maior número de relações - e suas 12 comunidades. As 8 principais comunidades estão destacadas cada uma em uma cor diferente. 


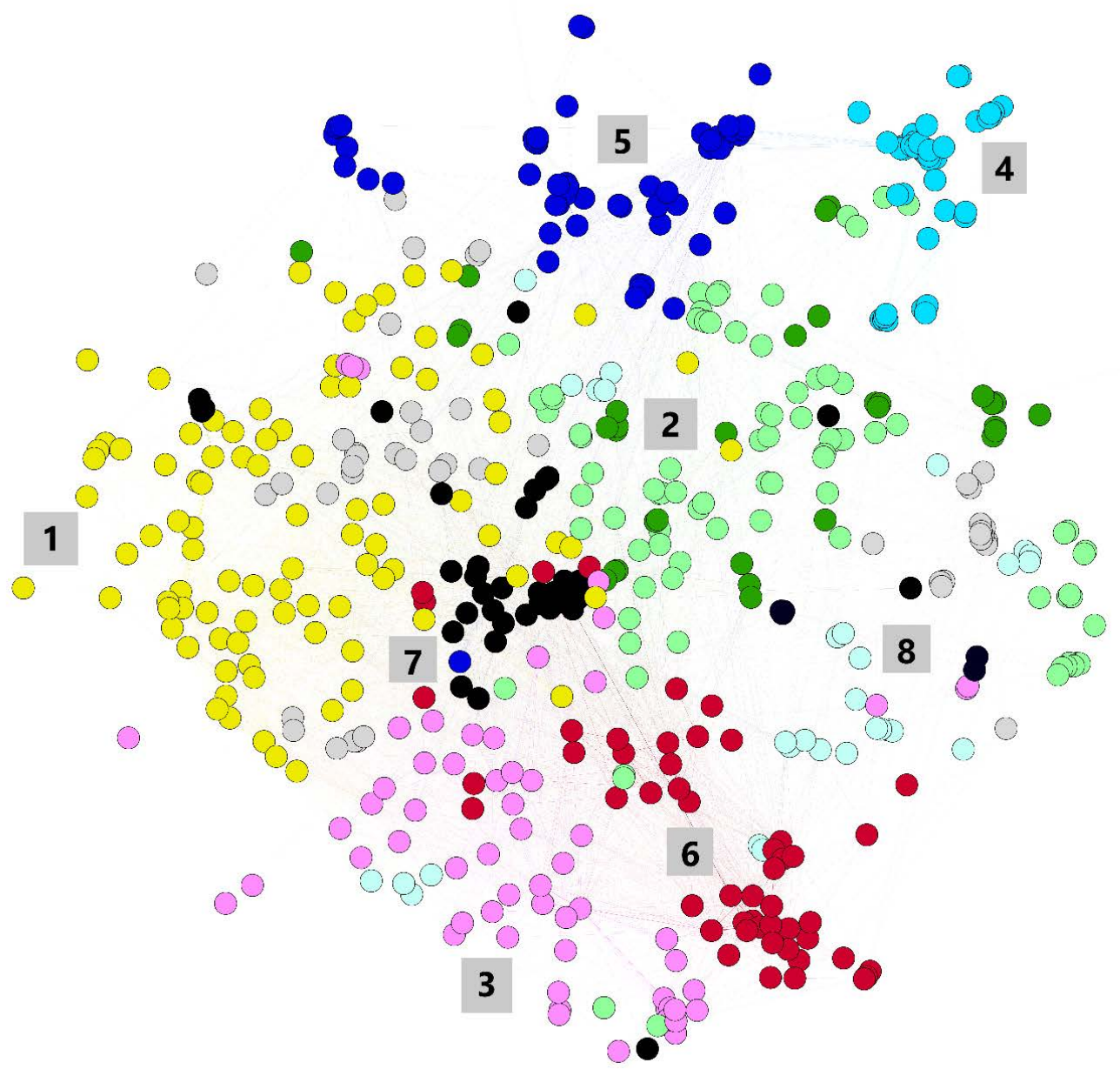

Figura 2 - Rede de acoplamento bibliográfico de artigos de pensamento social no Brasil (2002-2020) Fonte: Dados da pesquisa (2020).

Algumas comunidades chegam a reunir muitos documentos - a comunidade 1, em amarelo, por exemplo, concentra 93 artigos ou 14\% do total de 664 -, ao passo que outras reúnem menos de 5\%. Para facilitar, vamos nos limitar aos agrupamentos principais, destacando os temas e/ou disciplinas mais importantes no interior de cada um. Antes de prosseguirmos, vale relembrar: a rede é composta por artigos cujos autores participaram dos GT na Anpocs e/ou SBS, o que não significa, portanto, que todos os artigos possam ser identificados como da área de pensamento social no Brasil. O mais usual é que os pesquisadores se identifiquem e tenham produções em diferentes especialidades. Sem necessariamente ser um problema, essa forma complexa de observar pode ser profícua para detectarmos o que há de interesse compartilhado e de diálogo no interior da(s) área(s). Além disso, permite um recorte por temática e não por autores e autoras clássicos da área de pensamento social no Brasil, como de costume. Salientamos ainda que os temas destacados serão fundamentais para um projeto futuro de uma seção no site da BVPS destinada a grandes temas para os quais pesquisadores da área de pensamento social no Brasil podem contribuir. Para identificarmos a que temáticas correspondem cada comunidade da rede, coletamos as palavras-chave indexadas pelos autores dos artigos e, para uma melhor visualização, geramos nuvens de palavras, conforme as Figuras de 3 a 8.

Comecemos pelas comunidades mais agrupadas e que ocupam as bordas da rede, conforme a Figura 2. Em amarelo, com 93 documentos, encontra-se a maior comunidade - comunidade 1, Figura 3 -, que reúne tanto perspectivas de análise, como sociologia dos intelectuais, sociologia da literatura, sociologia da cultura 
e campo intelectual, quanto temas e/ou autores como objeto de pesquisa (identidade nacional, arte, Antonio Candido, Joaquim Nabuco etc.). A Figura 4 em verde claro (comunidade 2), formada por 87 documentos, temos os artigos cujos temas mais recorrentes (democracia, liberalismo, eleições e autoritarismo) se ligam ao campo de "pensamento político brasileiro"29. Com 59 documentos, a Figura 5, comunidade 3, em lilás, é formada sobretudo por temas caros à teoria social (modernidade, mudança social, imigração e desenvolvimento) e à história das ciências sociais no Brasil (Amazônia, estudos de comunidade, sociologia no Brasil e memória). Mais destacado do resto da rede, em azul-médio, temos o cluster dos 42 artigos majoritariamente dedicados a temas clássicos da ciência política (Figura 6, comunidade 4), em particular ao estudo das instituições (partidos políticos, forças armadas, eleições) e de seus formatos (democracia, centralização, descentralização) ${ }^{30}$. Ainda neste agrupamento, um termo fundamental é 'cultura política', em grande medida associada aos comportamentos dos indivíduos e instituições.

Com 58 artigos, a Figura 7, comunidade 5, colorida de azul-escuro, tem temáticas associadas à subárea designada de sociologia política, cujas temáticas se associam às discussões sobre movimentos sociais e ativismo transnacional ${ }^{31}$, mas também sobre gênero, sexualidade, mídias digitais e internet. A Figura 8, comunidade 6, em vermelho, com 53 documentos, reúne artigos que versam sobre a história das ciências sociais, nation-state-making (processo de formação do Estado nacional), história das ciências e da saúde.

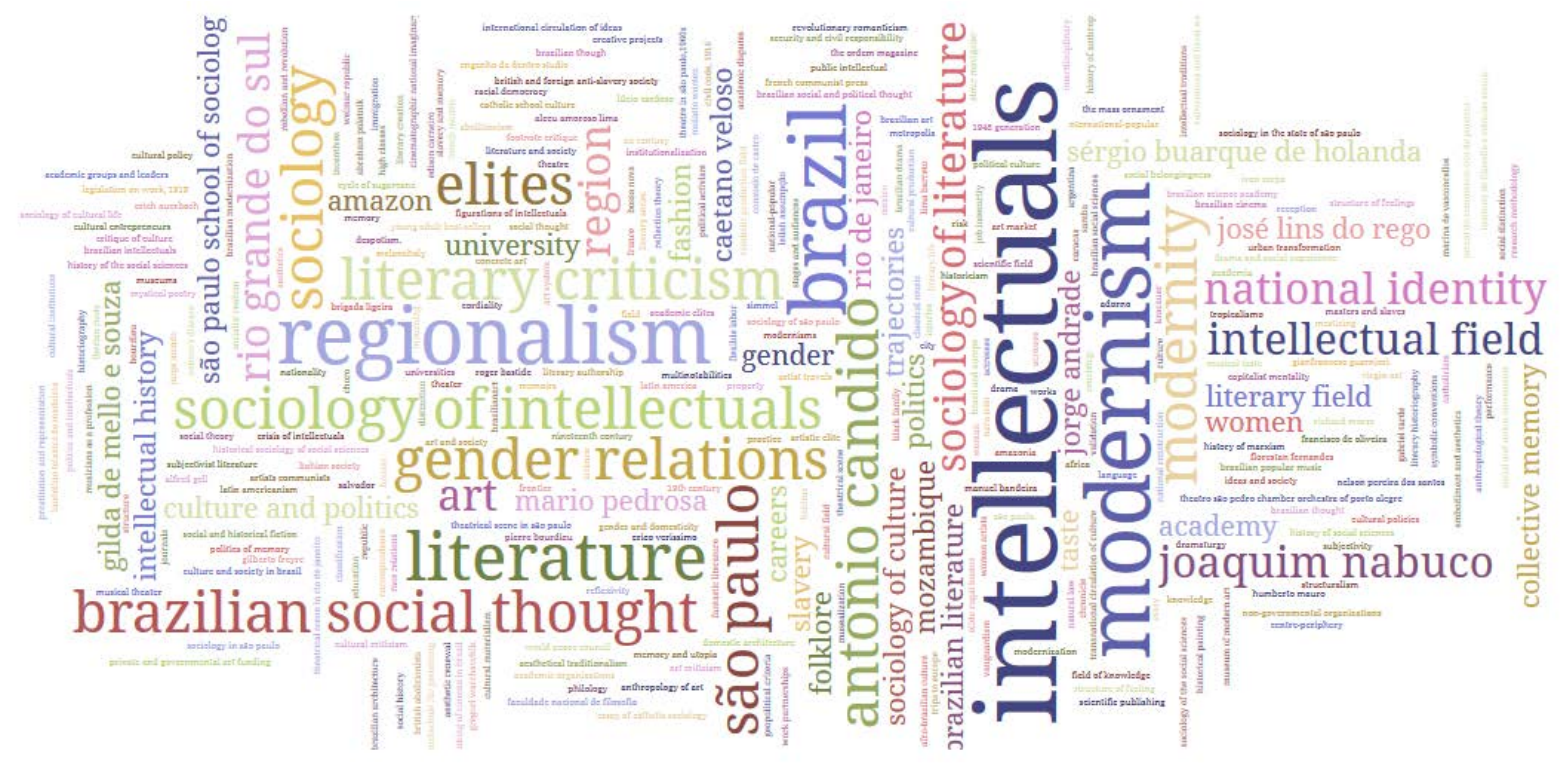

Figura 3 - Comunidade 1 em amarelo: nuvem de palavras-chave dos autores (2002-2020)

Fonte: Dados da pesquisa (2020). 


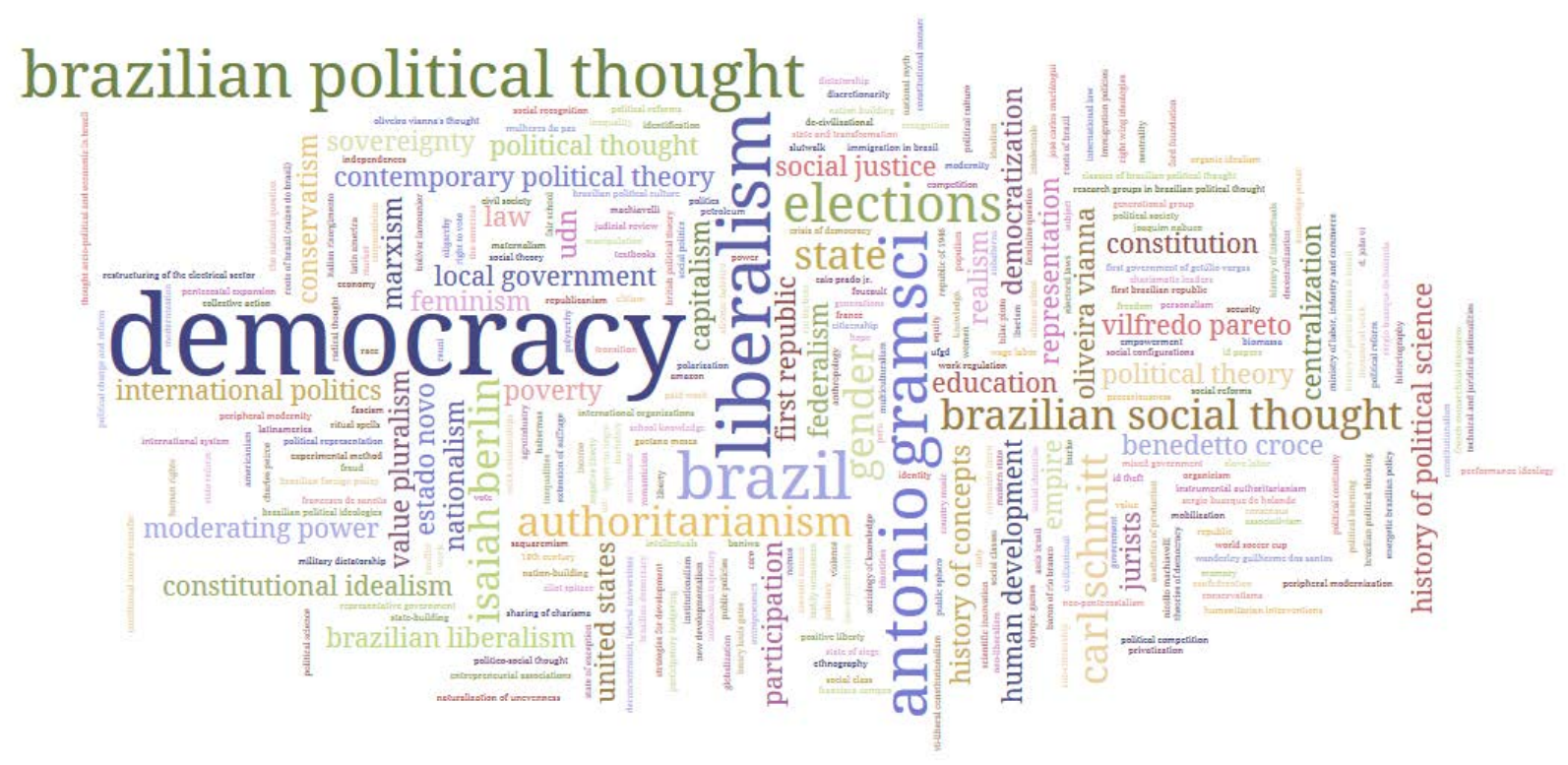

Figura 4 - Comunidade 2 em verde-claro: nuvem de palavras-chave dos autores (2002-2020) Fonte: Dados da pesquisa (2020).

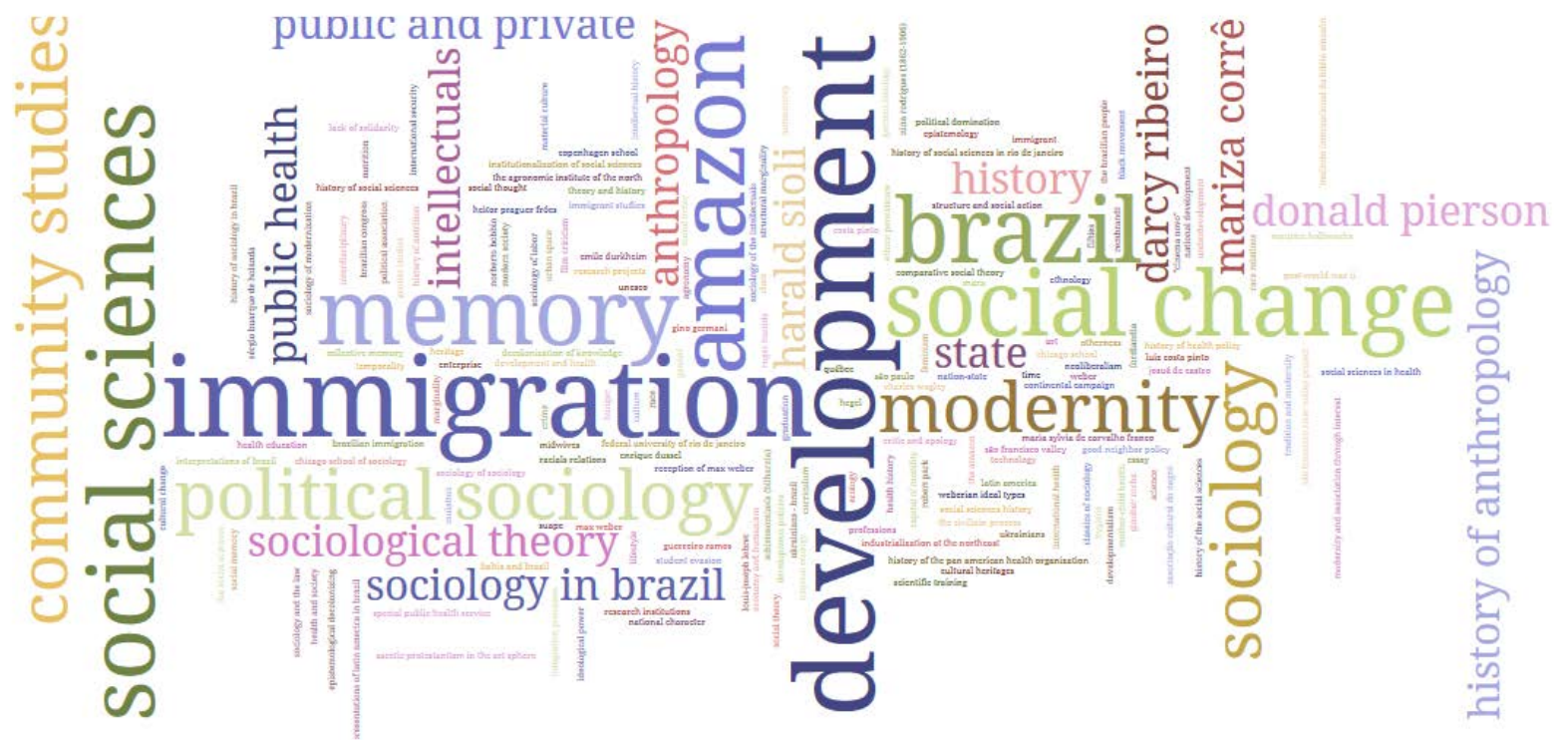

Figura 5 - Comunidade 3 em lilás: nuvem de palavras-chave dos autores (2002-2020) Fonte: Dados da pesquisa (2020). 


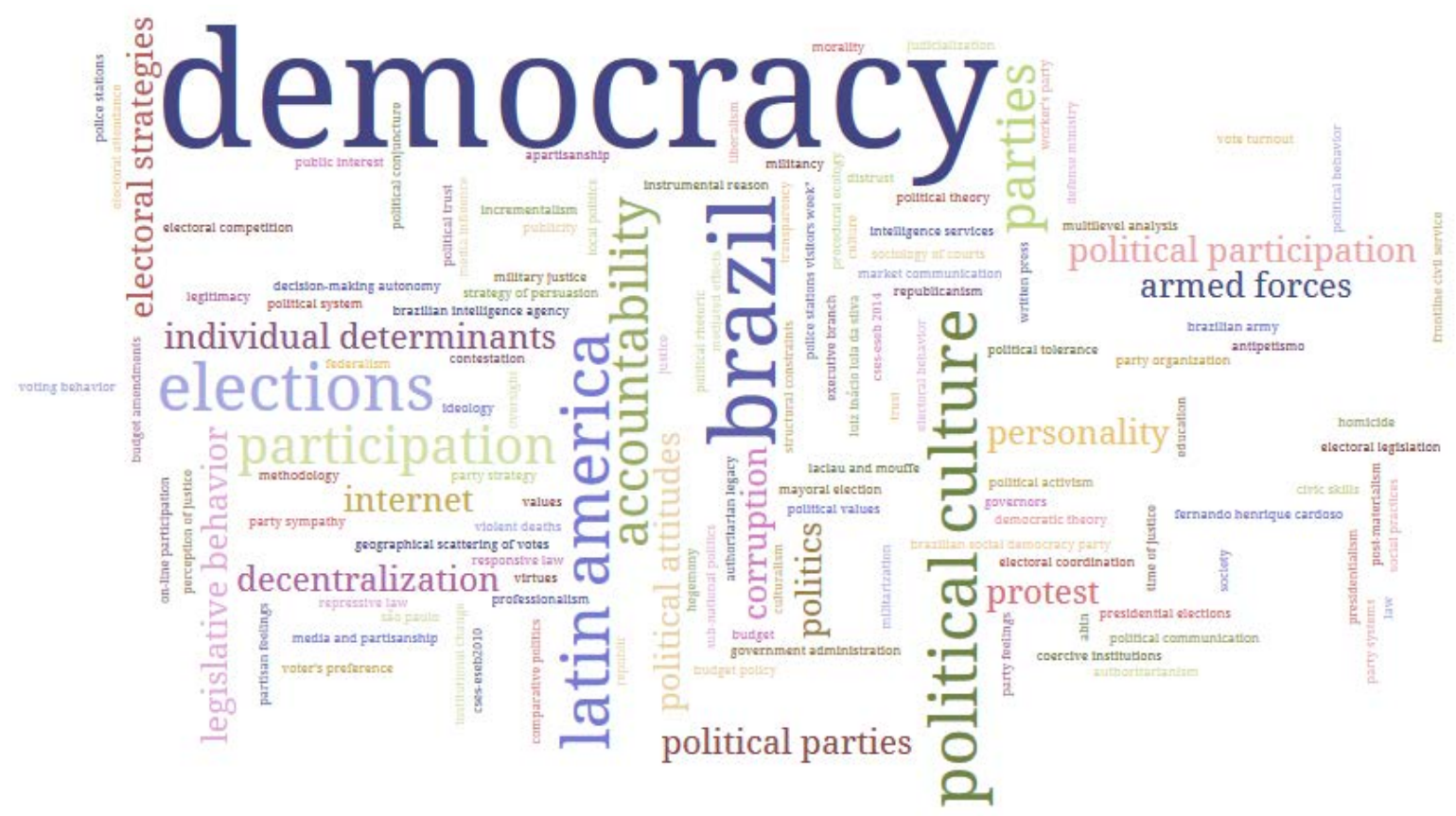

Figura 6 - Comunidade 4 em azul-médio: nuvem de palavras-chave dos autores (2002-2020)

Fonte: Dados da pesquisa (2020).

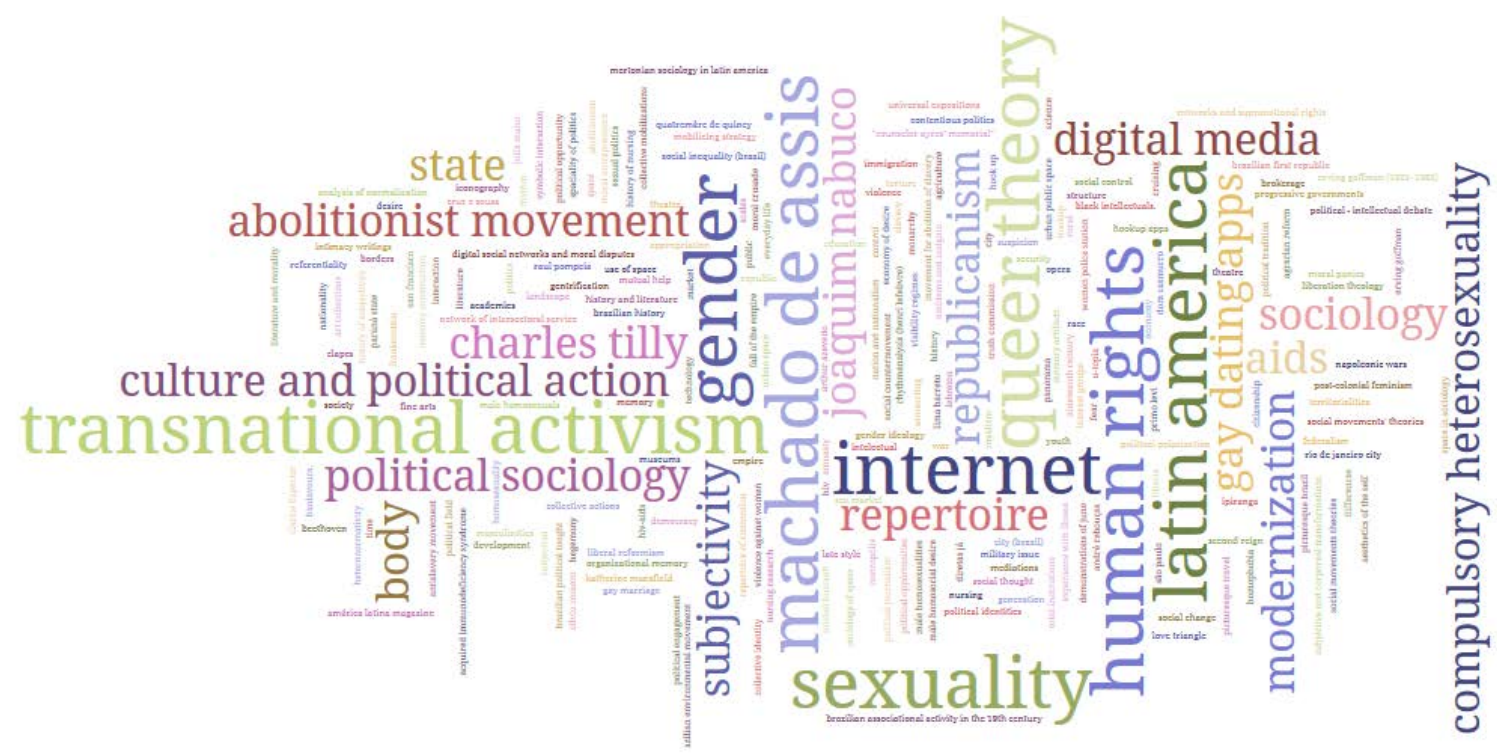

Figura 7 - Comunidade 5 em azul-escuro: nuvem de palavras-chave dos autores (2002-2020)

Fonte: Dados da pesquisa (2020). 


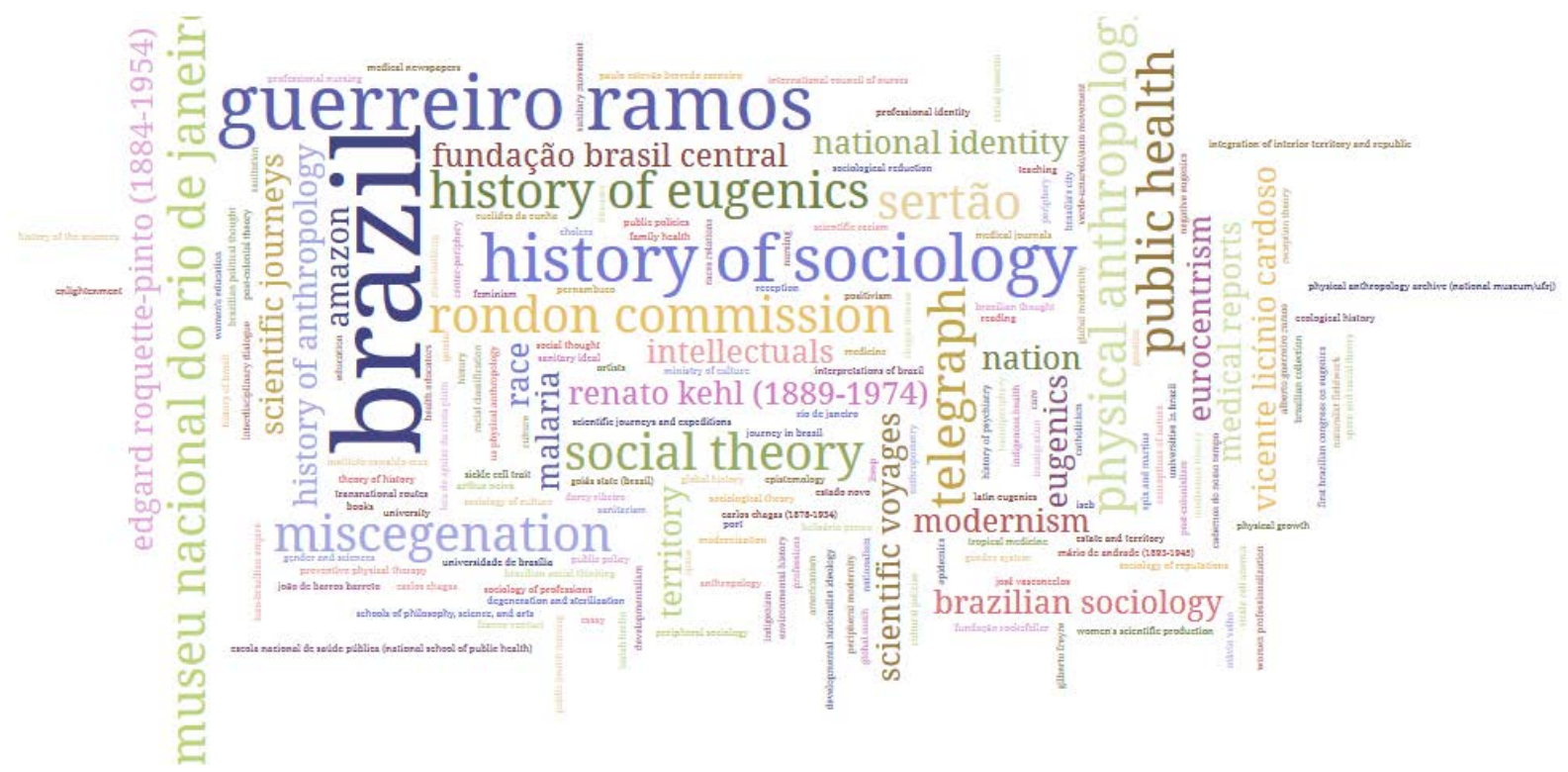

Figura 8 - Comunidade 6 em vermelho: nuvem de palavras-chave dos autores (2002-2020) Fonte: Dados da pesquisa (2020).

Passemos, agora, para as comunidades que, embora menos agrupadas e com menos artigos em relação às demais, ocupam posições importantes na rede da Figura 2, sobretudo porque estão localizadas na interseção entre comunidades. A primeira delas é a ilustrada em preto (comunidade 7), com 39 documentos, cujas palavras-chave estão associadas ao modernismo e a movimentos da cultura brasileira de forma geral, à discussão sobre o ensaísmo e a produção anterior à institucionalização das ciências sociais no Brasil, e à relevância da comparação enquanto recurso metodológico ${ }^{16,23,32}$. Por fim, cabe destacar a comunidade em azul-claro (comunidade 8), com 31 documentos, dedicada à questão racial, traço fundante da sociedade brasileira, e tema perene das grandes interpretações do Brasil e das ciências sociais brasileiras. Outro dado que aponta para a sua relevância na área de pensamento social no Brasil é que seus artigos se encontram relativamente espalhados pela rede, na interseção de diversas comunidades. Defato, os temas das comunidades 7 e 8 são, digamos, fundantes da área de pensamento social ${ }^{16,23,32}$, e se revelam ainda hoje como mediadores importantes entre discussões distintas de que se ocupam seus pesquisadores, como demonstram as relações de acoplamento bibliográfico. As Figuras 9 e 10 revelam as palavras-chave de cada comunidade:

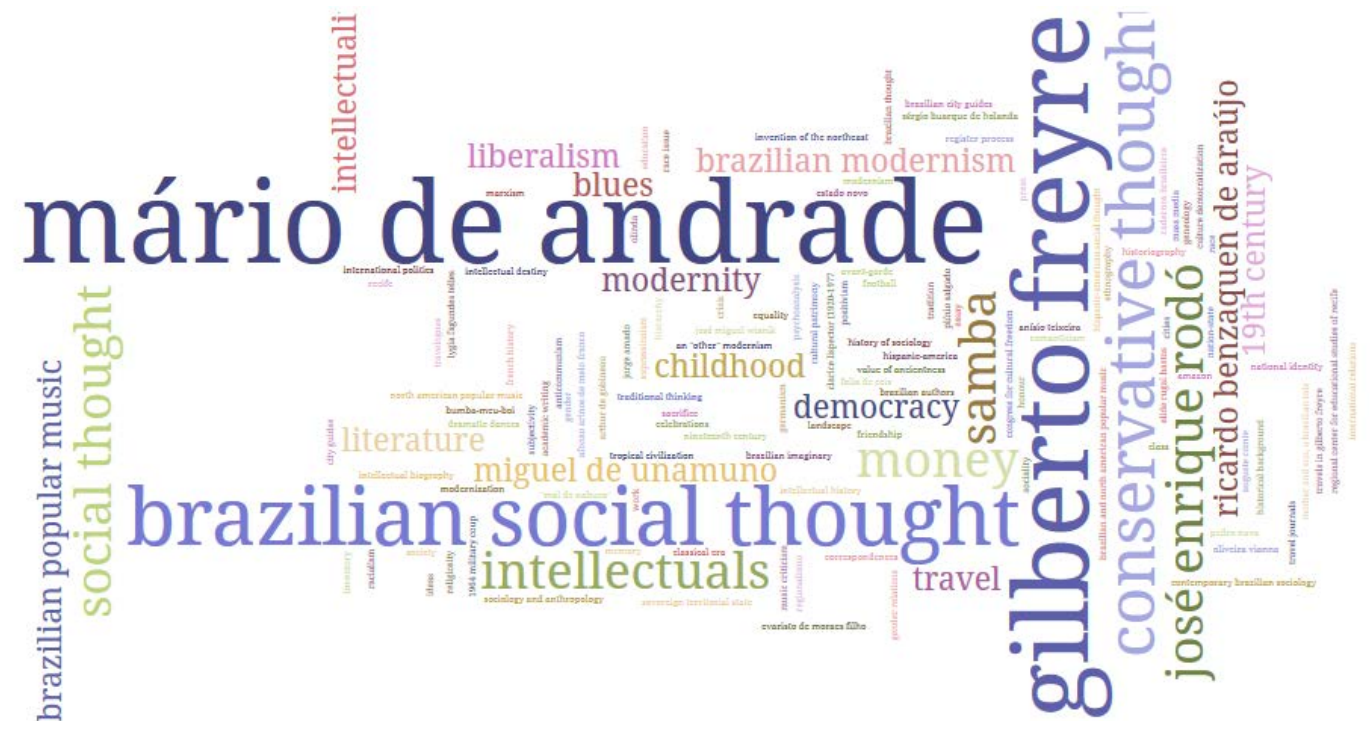

Figura 9 - Comunidade 7 em preto: nuvem de palavras-chave dos autores (2002-2020)

Fonte: Dados da pesquisa (2020). 


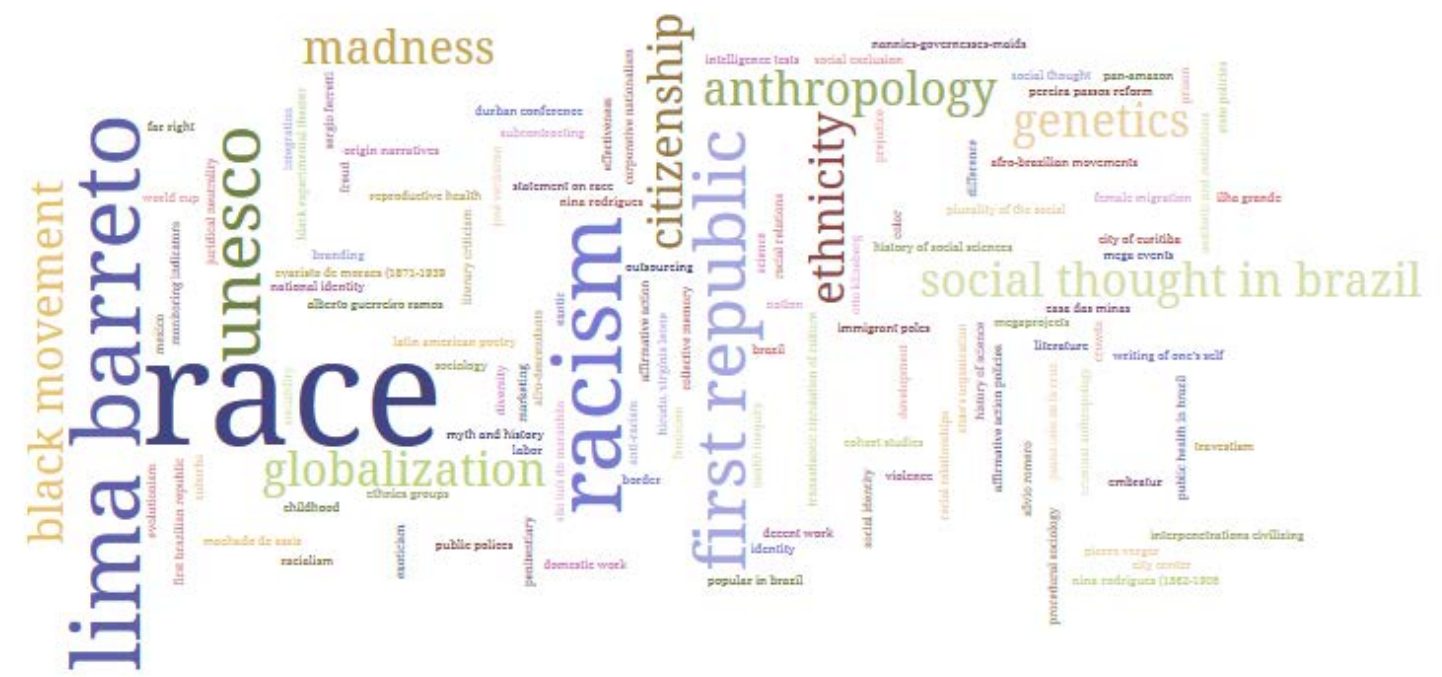

Figura 10 - Comunidade 8 em azul-claro: nuvem de palavras-chave dos autores (2002-2020)

Fonte: Dados da pesquisa (2020).

Outra forma possível de detectar os temas da área de pensamento social no Brasil se dá pela análise de cocitação. A seguir, modelaremos a rede de cocitação dos autores mais citados no interior dos 664 documentos, destacando o label apenas dos chamados 'intérpretes', isto é, os produtores intelectuais tomados como referência para a pesquisa na área. A fim de facilitar a visualização e a limpeza dos dados, restringimos a visualização dos nomes com mais de 10 citações neste conjunto de documentos - advertência fundamental pois revela as limitações da análise a seguir -, gerando uma lista de 233 nomes diferentes.

Ainda que o debate acumulado na área nos últimos anos venha descentrando os 'grandes intérpretes do Brasil' como unidade autoevidente de pesquisa, vale registrar a relevância de suas formulações para as pesquisas atuais, seja como objetos de estudo, seja como repertórios cognitivos a que recorrem os pesquisadores para a compreensão de fenômenos sociais do passado e do presente. Isso porque, longe de serem registros datados, as interpretações do Brasil revelam pujança justamente porque os processos pretéritos sobre os quais se debruçaram ainda nos dizem respeito. E no esforço de tentarem compreender a formação da sociedade brasileira, seus impasses, conflitos e acomodações, forjaram visões distintas sobre ela, orientando em maior ou menor grau práticas de indivíduos e grupos ${ }^{24,33}$.

$\mathrm{Na}$ Figura 11 apresentamos a rede de cocitação de autores citados ao menos 10 vezes nas referências bibliográficas dos artigos de nossa amostra. A partir dela, pode-se visualizar como o cânone de pensamento social no Brasil, formado sobretudo por autores como Gilberto Freyre, Caio Prado Jr., Sérgio Buarque de Holanda, Antonio Candido e Florestan Fernandes, é ainda muito presente nas pesquisas evidenciadas pelos artigos. Embora a construção de um cânone não seja aleatória, porque associada a relações cognitivas e a práticas científicas mais ou menos estabelecidas, é possível capturar parte de sua dinâmica por meio do processo de revisão e ampliação dos autores e autoras que o integram. Por essa razão, esse constante movimento de inclusão - e, claro, de exclusão - de um cânone revela seleções cognitivas feitas no interior de uma área de pesquisa, direcionando os focos para determinadas questões analíticas e empíricas ${ }^{\text {iv }}$. Nesse sentido, pode-se dizer que autores e obras canônicos se constituem também em instâncias importantes de auto-observação da área, permitindo que pesquisadores ganhem perspectiva sobre suas práticas e escolhas rotineiras.

Dito isso, é possível perceber na Figura 11 como se entrelaçam em comunidades específicas autores consagrados e outros que começam a ser inseridos no cânone, movimento a que aludimos acima. O maior

iv Para uma discussão sobre a ideia de cânone feita na chave da "leitura distante", vale conferir os trabalhos de Franco Moretti ${ }^{34}$. 
grupo, em azul, reúne nomes como Antonio Candido (173 citações), Gilberto Freyre (131), Mario de Andrade (82), Sérgio Buarque de Holanda (61), Alceu Amoroso Lima (35) e Caio Prado Jr. (26). O nosso ensaísmo se encontra aí bem representado, com os nomes mais 'canônicos' do pensamento social no Brasil. Já o grupo verde reúne basicamente os principais nomes da geração pioneira das ciências sociais institucionalizadas no Brasil, como Florestan Fernandes (191 citações, o mais citado de todos), Fernando Henrique Cardoso (50), Roger Bastide (41), Octavio Ianni (37), Maria Isaura Pereira de Queiroz (35), Charles Wagley (32) e Donald Pierson (29). Por fim, o grupo laranja, mais centrado no 'pensamento político brasileiro', ainda que não exclusivamente, congrega Raymundo Faoro (91 citações), Guerreiro Ramos (89), Joaquim Nabuco (51), Oliveira Vianna (48), Afonso Arinos de Melo Franco (47), Celso Furtado (36), entre outros. Ainda chamam a atenção mais dois grupos: um em rosa, com nomes de escritores como Lima Barreto (30 citações), e outro na cor vinho, abarcando autores ligados ao debate racial no primeiro terço do século XX, como Edgard Roquette-Pinto (43 citações), Euclides da Cunha (21) e Renato Kehl (17).

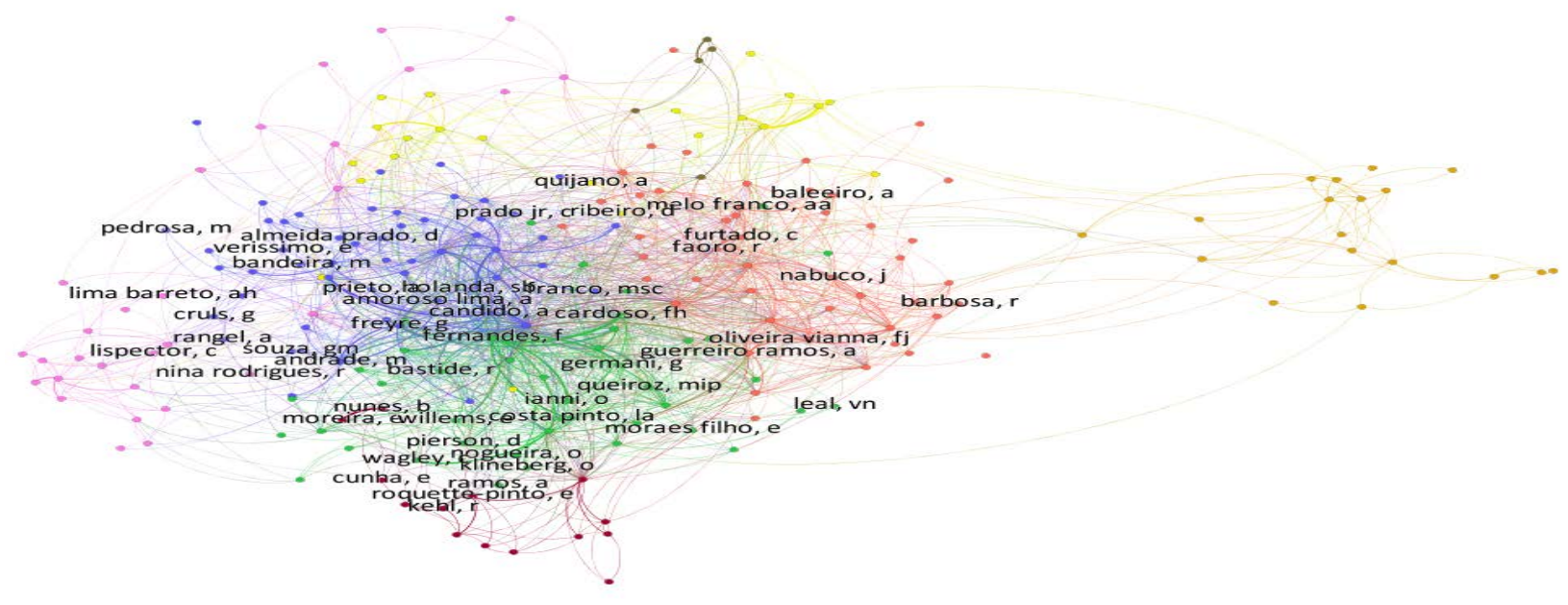

Figura 11 - Rede de cocitação de 'intérpretes' referenciados nos artigos de pensamento social no Brasil (2002-2020)

Fonte: Dados da pesquisa (2020).

A análise de cocitações também permite revelar como a própria dinâmica da área de pesquisa em 'pensamento social no Brasil' vai tecendo relações entre os seus pesquisadores, como na imagem a seguir. Afinal, já há um acúmulo considerável de análises sobre as 'interpretações do Brasil', que vai sendo acionado nos artigos que se debruçam sobre este material textual. Não temos aqui nenhuma pretensão de hierarquizar os autores em uma lista de importância, pois o que nos interessa é, ao reproduzir as mesmas posições estruturais da rede ilustrada na Figura 12 - destacando agora apenas os labels dos pesquisadores ligados a esse campo com maior ou menor intensidade -, ver como eles se posicionam nas comunidades apontadas anteriormente. Os pesquisadores se reúnem, grosso modo, em torno de regiões disciplinares, como a antropologia (comunidade em rosa), a sociologia (comunidade em verde), a ciência política (comunidade em vermelho), e sub ou interdisciplinares, como a sociologia política (comunidade em amarelo) e a história da ciência e da saúde (comunidade em vinho). E, justamente localizados na comunidade em azul, encontrase um grupo de pesquisadores de diferentes disciplinas voltados à investigação (em sentido ampliado) da cultura brasileira, incluindo as obras de ensaístas, artistas, literatos e demais produtores de bens simbólicos. 


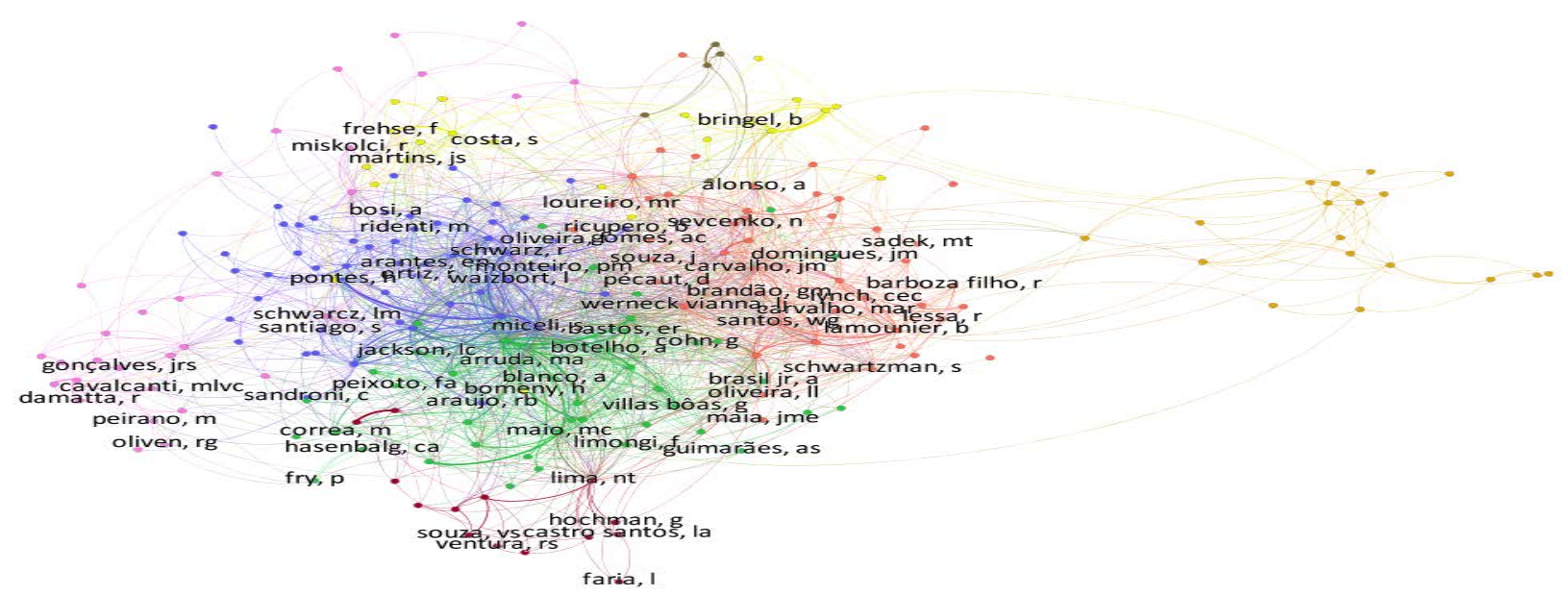

Figura 12 - Rede de cocitação de pesquisadores referenciados nos artigos de pensamento social no Brasil (2002-2020)

Fonte: Dados da pesquisa (2020).

Ao fim e ao cabo, menos que reforçar distinções rígidas, a modelagem da rede de cocitação de autores exprime as relações entre textos que se encontram subjacentes à produção de conhecimento na área de pensamento social no Brasil, pelo menos com base na 'atividade citante' dos seus praticantes. Os nomes dos autores citados são formas de simplificação da matriz de relações entre textos, posto que a unidade de agregação não é o elemento citado, mas o conjunto de elementos bibliográficos escritos por um mesmo autor. Portanto, estas relações entre nomes não se traduzem automaticamente em relações sociais entre os autores; ou melhor, são relações cognitivas que identificam as principais interações entre os recursos textuais que conformam a área de pesquisa.

As palavras-chave, os nomes dos 'intérpretes' e a identificação de pesquisadores permitem, por meio das técnicas de 'leitura distante' aqui empregadas, sugerir uma espécie de vocabulário-básico que define mesmo que de modo experimental - a área de pensamento social. Este vocabulário pode ajudar a definir termos de busca que, de modo recursivo, levarão à ampliação da amostra de 664 artigos aqui usada como 'representativa' desse campo do conhecimento. Se a construção do nosso corpus partiu de um critério de pertinência extratextual - a frequência de pesquisadores em dois grupos de trabalho da área -, o desafio agora é mobilizar os nossos resultados de pesquisa para definir um conjunto específico de termos que possa constituir uma imagem ampliada da produção intelectual da área.

\section{UM MAPA SEMÂNTICO DA ÁREA DE PENSAMENTO SOCIAL NO BRASIL: DIÁLOGOS E TENDÊNCIAS}

Para melhor qualificar as relações de acoplamento bibliográfico entre os artigos da área de pensamento social no Brasil, recorremos às palavras-chave indexadas pelos próprios autores para identificar as diferentes comunidades. Nesta seção, analisaremos, agora por diversos ângulos, os termos, conceitos e temas que se revelam a partir do material colhido. De maneira diferente, portanto, de uma análise de conteúdo, entendida estritamente enquanto contagem da frequência das palavras, buscaremos realizar um mapeamento semântico dos conceitos, categorias e temas da área ao longo do tempo ${ }^{35}$. Assim, esperamos fornecer um panorama, a um só tempo amplo e detalhado, da semântica da área - dentro dos limites já aludidos de nossa amostra.

As palavras-chave podem ser consideradas uma das formas pelas quais os pesquisadores de uma área compreendem suas pesquisas dentro de um campo temático. Elas se constituem, portanto, em um indício - e não um retrato fiel - das discussões, tendências e disputas cognitivas. Na seção anterior, utilizamos 
as palavras-chave para dotar de inteligibilidade as comunidades formadas na rede de acoplamento bibliográfico. Mudaremos nosso foco e passaremos, aqui, a abordar as palavras-chave nas relações que estabelecem entre si e ao longo do tempo. Na Figura 13, é possível acompanhar como elas se distribuem no período de 2002 a 2019.

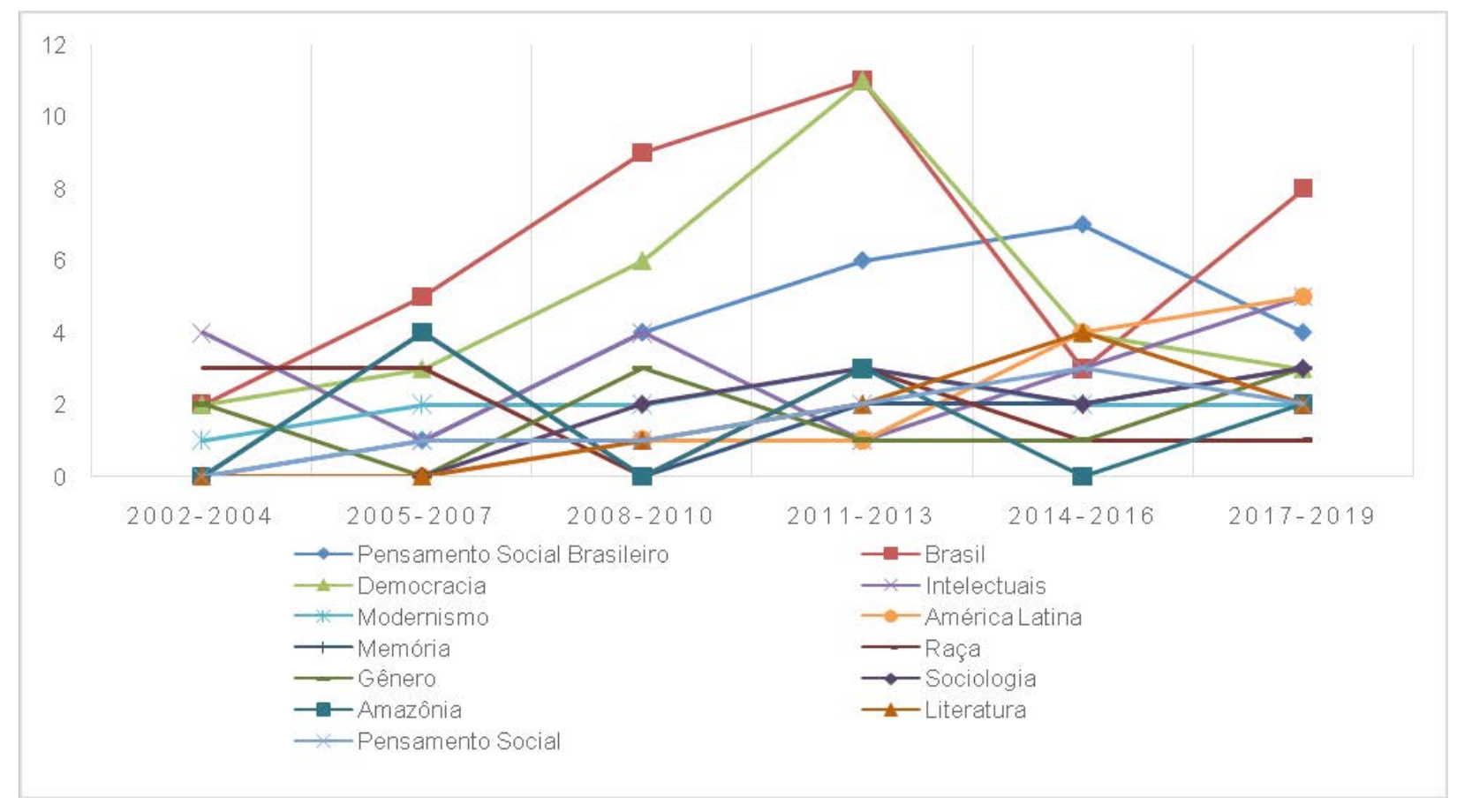

Figura 13 - Palavras-chave mais frequentes indexadas pelos autores dos artigos (2002-2019) Fonte: Dados da pesquisa (2020).

É possível dizer que, entre as treze palavras-chave (indexadas pelos autores dos artigos) mais recorrentes entre os artigos selecionados, algumas tiveram forte impulso nos últimos triênios. São os casos dos termos 'América Latina', 'intelectuais', 'literatura' e 'gênero', para além dos mais óbvios 'pensamento social', 'pensamento social no Brasil' e 'Brasil'. Cada uma dessas palavras-chave se refere a algumas das tendências de pesquisa do pensamento social - e, em alguma medida, da sociologia. A primeira dessas tendências se refere à aposta na comparação como meio heurístico de compreensão das condições e possibilidades da prática sociológica e da teoria social em países periféricos. O exercício de se voltar ao vasto e rico acervo de autores e obras latino-americanos, tornou-se uma forma de melhor calibrar, em relação às teorias dos países centrais, as análises de fenômenos do continente ${ }^{21,36,37}$. As pesquisas sobre intelectuais sempre foi, na área de pensamento social no Brasil, uma de suas principais preocupações, até porque, em sociedades altamente desiguais, como a nossa, essa camada social costuma ter uma relevância e mesmo um protagonismo político mais intenso do que em outras paragens ${ }^{33,38}$. É possível perceber como os artigos que indexam 'intelectuais' em suas palavras-chave têm forte alta a partir do triênio 2014-2016, em razão talvez do desenrolar dos acontecimentos de junho de 2013, mantendo a crescente até o triênio seguinte, 2017-2019, estimulados então pela polarização política e pela volumosa onda conservadora no Brasil e no mundo. Outra frente de pesquisa tradicional do pensamento social e que tem recebido ainda mais impulso é o seu diálogo com os estudos literários, como indicam os termos 'literatura' e 'modernismo'. Se uma das principais questões perseguidas pelo pensamento social é a investigação das interpretações do Brasil, a literatura e os literatos não poderiam ficar de fora, tendo em vista que foram - e em grande medida continuam a ser - fundamentais na criação de formas de imaginação nacional. Por fim, é importante destacar como a presença do termo 'gênero' entre as palavras-chave indicam uma das principais frentes de diálogo do pensamento social com 
outras especialidades, revelando o esforço de alargar o cânone dos autores clássicos ou das questões que vêm constituindo esse campo disciplinar ${ }^{39-41}$.

Ainda no que toca às frequências das palavras-chave durante o período destacado, gostaríamos de fazer mais algumas observações: o termo 'democracia' vinha tendo forte alta entre 2002 e 2013. A razão mais plausível para queda a partir no triênio 2014-2016 se deve, acreditamos, ao contexto político mais recente da sociedade brasileira e latino-americana de acentuada desdemocratização e de interesse crescente das ciências sociais de forma geral pelos movimentos conservadores e autoritários. Quanto ao tema da questão racial, já foi dito que sua discussão é perene na área de pensamento social, sobretudo devido à relevância que diversos autores deram a ela em suas interpretações do Brasil e ao peso estrutural que ela teve na formação da sociedade brasileira e tem até hoje. Como vimos na seção anterior, é interessante notar como, apesar de um número reduzido de artigos em relação às demais temáticas, o tema 'racial' no pensamento social tem função de mediação entre diferentes comunidades justamente porque através dessa questão se unem outras diversas. Isso nos adverte para como a simples frequência de uma palavra não pode ser indício exclusivo para aferir a importância de um tema ou categoria, mas é preciso também atentar para a posição que ocupa no campo de relações semânticas.

Uma outra forma de colocarmos as palavras-chave em relação é o mapa temático ${ }^{42}$. Para gerá-lo, utilizamos o pacote Bibliometrix do software R e sua interface Biblioshiny ${ }^{43}$ e selecionamos as 400 palavras-chave dos autores que tenham, no mínimo, três repetições no corpus. Cada comunidade recebeu como rótulo as três palavras-chave mais citadas em seu interior. Na Figura 14, é possível observar que as palavras-chave são ordenadas em comunidades temáticas. Para chegar a essa visualização, o mapa é definido por dois eixos: um vertical (métrica de densidade das palavras-chave) e outro horizontal (métrica de centralidade das palavras-chave). A métrica de densidade mede a força dos laços internos entre todas as palavras-chave que descrevem determinado tema. Por sua vez, a métrica de centralidade fornece medidas de como a comunidade se posiciona em relação às demais - se se trata de um tema mais central, que se liga a outros temas, ou mais periférico. O mapa temático é uma forma de visualização que une frequência - o tamanho dos círculos revela a quantidade de termos associado a cada comunidade de palavras-chave - e posição relacional em um campo semântico - a localização de acordo com os eixos densidade e centralidade. 


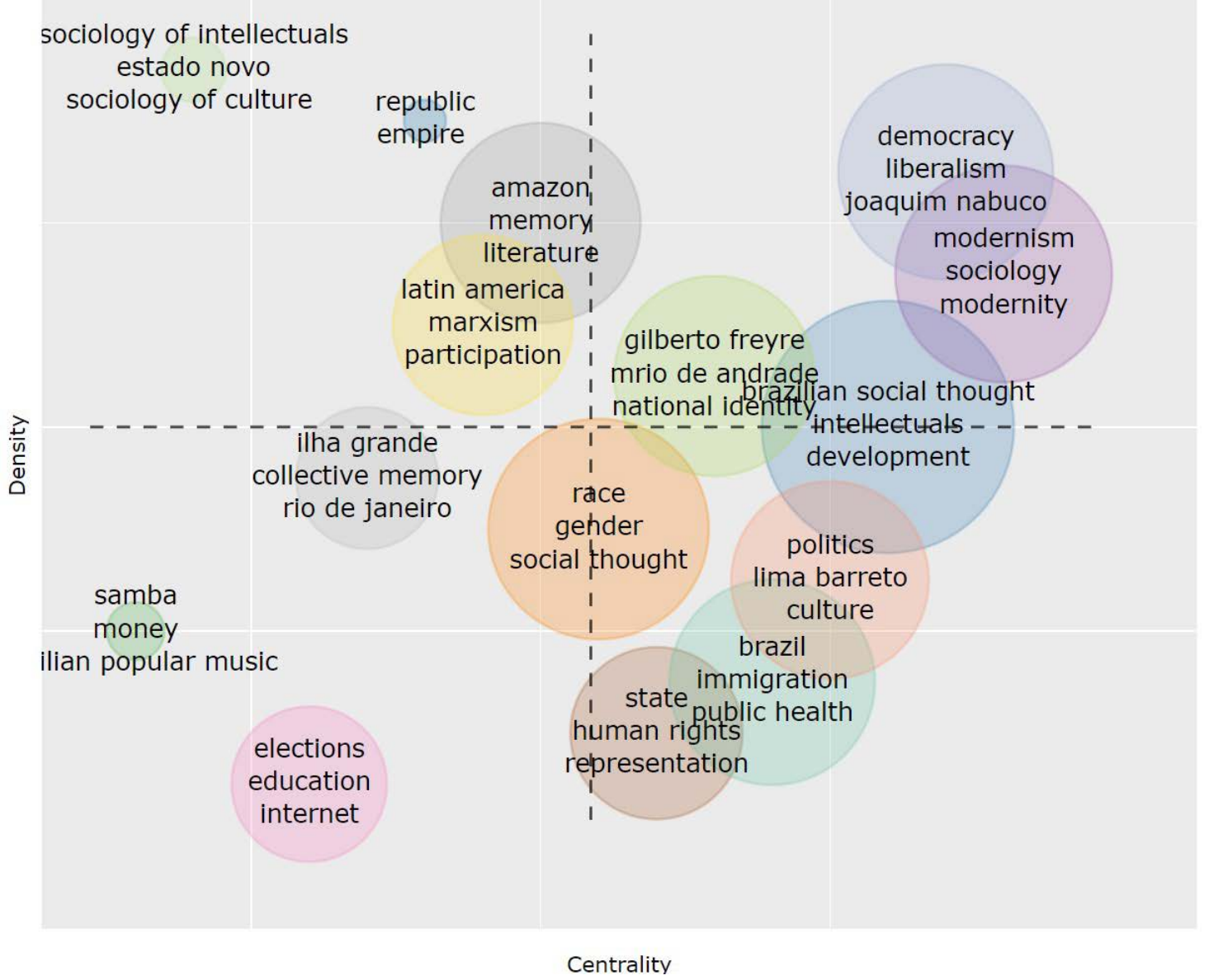

Figura 14 - Mapa temático de palavras-chave dos autores (2002-2020) Fonte: Dados da pesquisa (2020).

O resultado é disposto em quatro quadrantes. O quadrante superior à direita é o que reúne as temáticas com as maiores métricas de centralidade e densidade e, portanto, com alto grau de laços internos entre as palavras-chave e de laços externos com outros temas. É caso de temas relacionados à institucionalização das ciências sociais no Brasil e às discussões relativas à cultura e à democracia no país, como 'modernismo' (13 menções) e 'sociologia' (12), 'modernidade' (11), 'identidade nacional' (7), 'democracia' (29), 'pensamento social no Brasil' (26) e 'intelectuais' (20). Os termos que se encontram no quadrante superior à esquerda têm laços internos fortes, mas quanto mais distantes do centro do mapa, menor a conexão com o restante das outras comunidades temáticas. São, portanto, termos que estão muito associados e tendem a refletir temas altamente centrados, denotando quase especializações dentro de uma especialidade. É o caso das discussões sobre a relação entre intelectuais e 'Estado Novo' (4 menções), 'América Latina' (16),'marxismo' (6) e 'Amazônia' (12). No quadrante inferior à esquerda se localizam os agrupamentos temáticos com baixa centralidade e densidade. Assim, podem indicar tanto a marginalidade ou o descenso de temas na área (como parece ser o caso de 'memória coletiva' (6 menções) e 'música popular brasileira' (3)), quanto temas emergentes ('internet' (5 menções) e 'educação' (7)). Por fim, no quadrante inferior direito, encontram-se aqueles termos que configuram agrupamentos temáticos com baixa densidade e alta centralidade. No limite, são termos que, embora possam ser agrupados em comunidades, sua principal característica reside na transversalidade de seus termos por todo o corpus de nossa amostra. É o caso de termos como 'cultura' (6 menções), 'política' (7) e 'Estado' (7), por exemplo. Merece nota a posição do agrupamento temático formado pelos termos 'gênero' (12 menções), 'raça' (13) e 'pensamento social' (11). Situado exatamente entre os quadrantes inferiores esquerdo e direito, diríamos que esse agrupamento revela temas emergentes que vêm se tornando transversais à área de pensamento social ou mesmo estimulando diálogos entre especialidades. 
Como em qualquer subárea das ciências sociais, a de pensamento social no Brasil congrega temas caros à sua constituição, inclusive ao eleger os autores clássicos que compõem o seu cânone. Contudo, parece significativo que a área tenha dinâmicas internas complexas e em complexificação, com agrupamentos temáticos distintos, mais ou menos centrados, e com significativos diálogos entre especialidades. Nesse sentido, parece razoável supor que a área vem se integrando a questões postas por outras especialidades a partir das discussões analíticas e metodológicas específicas a ela.

\section{A AUTO-OBSERVAÇÃO DA ÁREA DE PENSAMENTO SOCIAL NO BRASIL: UMA AGENDA DE PESQUISA}

A análise preliminar da área de pensamento social no Brasil via artigos acadêmicos indexados na base SciELO Citation Index/Web of Science é uma das diversas frentes de pesquisa em andamento no âmbito da BVPS. Ela cumpre uma importante etapa, ainda que incipiente, na qual se unem aspectos metodológicos e analíticos. Quanto aos primeiros, estamos cientes de que os artigos não fornecem um retrato de corpo inteiro da área e, por isso, buscamos uma primeira aproximação de um objeto empírico que, pela sua dinamicidade e complexidade, não é de fácil captura. Ao recuperarmos os temas de interesse dos pesquisadores, suas formas de indexação - via palavras-chave - e citação - via referências bibliográficas -, estamos apenas construindo as bases para um novo ponto de partida que nos permitirá rastrear com maior rigor metodológico os raios de interações do pensamento social com outras especialidades das ciências sociais e humanas. Pois, se é certo que determinadas perspectivas analíticas - relação entre ideias e vida social - e temas - interpretações e intérpretes do Brasil -, são recorrentes na área, isso não significa que elas demarquem fronteiras rígidas. É sempre muito difícil definir até onde vão os limites de uma área do conhecimento e, no caso do pensamento social, isso parece ainda menos possível. Supomos, ao contrário, que talvez advenha dessas interações com temas caros a outras especialidades sua principal contribuição às ciências sociais brasileiras ${ }^{16}$. Daqui para frente, caberá, com o levantamento que temos, investigar como temas e perspectivas caros ao pensamento social interpelam outras especialidades e, em sentido inverso, qual o lugar do pensamento social nas discussões de temas afins a essas especialidades.

Junto com as considerações de ordem metodológica, existem as de ordem analítica. Até agora estamos calcados nos dados colhidos e naquilo que nos foi possível observar através das seleções cognitivas operadas pelas pesquisas da área de pensamento social. Ao nos limitarmos aos artigos, sabemos que outros tantos temas, categorias e tendências da área certamente ficaram na penumbra. Longe, portanto, de nutrirmos uma confiança absoluta nos dados, apostamos que eles podem nos ajudar a criar novas formas de observação, inclusive ao estender a análise a materiais até agora pouco convencionais em mapeamentos similares a este que estamos realizando, a exemplo dos projetos de pesquisa, artigos em jornais e ementas de disciplinas. Esse é o desafio com que nos defrontamos no interior do projeto da BVPS de preservação, indexação e disponibilização de diversos documentos da área de pensamento social. Na busca de enfrentá-lo, esperamos intensificar os diálogos entre Sociologia, Cientometria e Biblioteconomia como forma de auto-observação de nossas práticas.

De modo algum tomamos esse esforço de mapeamento como um resultado definitivo. Mas, como toda a análise que pretende capturar a dinâmica científica, uma etapa fundamental que deve subsidiar a definição de critérios de seleção do que deve entrar no acervo da BVPS. Neste sentido, se bem sucedido, esse mapeamento estabelecerá alguns parâmetros para novos mapeamentos futuros que, inevitavelmente, uma biblioteca virtual como a BVPS está comprometida a realizar. Quanto ao que fica 'de fora', acreditamos que com a publicização das formas de seleção dos documentos, sobretudo artigos, podemos ampliar o debate junto com os pesquisadores da área de pensamento social no Brasil do que ainda pode e deve ser integrado ao acervo da BVPS. Expor o que estamos observando - seus limites e vieses -, via o mapeamento aqui 
realizado, é o que nos permitirá perseguir no futuro novos meios de ver o que não vemos ${ }^{44}$. É preciso ainda ressaltar que a BVPS, como as demais bibliotecas virtuais do Centro Latino-Americano e do Caribe de Informação em Ciências da Saúde (Bireme), dispõe de estatísticas de visualização e acesso que fornecem ainda mais dados sobre o perfil dos seus frequentadores e os conteúdos de maior apelo. Isso é fundamental para acompanharmos o fluxo de informação e como o que é disponibilizado pela BVPS é recepcionado pelo nosso público.

Para finalizar, não se trata, é óbvio, de entender que o tipo de análise e de auto-observação aqui ensaiados substituirão os modos habituais de reflexão sobre as ciências sociais, nas quais o tradicional balanço bibliográfico é sem dúvida fundamental ${ }^{45}$. A 'leitura distante' implica um outro objeto de conhecimento, que permite a detecção de tendências e padrões estruturais de outro modo inapreensíveis. E, como adverte Niklas Luhmann, as comunicações voltadas para a auto-observação, justamente ao serem comunicadas, alteram o que é observado ${ }^{46}$. Em suma, nosso intuito aqui é criar uma espécie de instância de 'autoirritação' do pensamento social no Brasil por meio de uma observação de outro tipo de sua dinâmica e funcionamento, o que poderá, quem sabe, abrir novas perguntas e problemas para a área de pesquisa.

\section{REFERÊNCIAS}

1. Arellano MA. Preservação de documentos digitais. Ci Inf. 2004 ago.;33(2):15-27.

2. Hammarfelt B. Beyond coverage: toward a bibliometrics for the humanities. In: Ochsner M, Hug SE, Daniel H-D, organizers. Research assessment in the humanities: towards criteria and procedures [Internet]. Cham: Springer; 2016 [cited 2020 May 13]. p. 115-31. Available from: https://doi. org/10.1007/978-3-319-29016-4_10.

3. Housley W, Procter R, Edwards A, Burnap P, Williams M, Sloan L, et al. Big and broad social data and the sociological imagination: a collaborative response. Big Data Soc [Internet]. 2014 July-Dec [cited 2020 May 13]:1-15. Available from: https://journals.sagepub.com/doi/10.1177/2053951714545135.

4. Leydesdorff L. Theories of citation? Scientometrics [Internet]. 1998 Sept [cited 2020 Aug 24];43(1):525. Available from: https://link.springer.com/article/10.1007/BF02458391.

5. Leydesdorff $\mathrm{L}$. The challenge of scientometrics: the development, measurement, and self-organization of scientific communications. [place unknown]: Universal-Publishers; 2001. 360 p.

6. Brasil Jr A, Carvalho L. O impacto da sociologia: cultura de citações e modelos científicos. No prelo. 2020;

7. Leydesdorff L. A sociological theory of communication: the self-organization of the knowledge-based society. [place unknown]: Universal-Publishers; 2001. 368 p.

8. Hedstrom M. Digital preservation: a time bomb for digital libraries. Comput Humanities. 1997 May;31(3):189.

9. Sayão LF. Uma outra face dos metadados: informações para a gestão da preservação digital. Enc Bibli: R Eletr Bibliotecon Ci Inf [Internet]. 2010 [citado em 2020 ago. 24]15(30):1-31. Disponível em: https:// periodicos.ufsc.br/index.php/eb/article/view/1518-2924.2010v15n30p1/19527.

10. Moretti F. A literatura vista de longe. Porto Alegre: Arquipélago; 2008.

11. Moretti F, Sobchuk O. Hidden in plain sight: data visualization in humanities. New Left Rev [Internet]. 2019 July-Aug [cited 2020 May 13]118. Available from: https://newleftreview.org/issues/II118/articles/.

12. González-Bailón S. Social science in the era of big data: social science in the era of big data. Pol Internet [Internet]. 2013 June [cited 2020 Aug 24];5(2):147-60. Available from: https://onlinelibrary.wiley.com/ doi/epdf/10.1002/1944-2866.POI328.

13. Luhmann N. La ciencia de la sociedad. Ciudad de México: Universidade Iberoamericana; 1996. 515 p.

14. Botelho A. The sociological invention of Brazil: essays and the social sciences. Am Soc [Internet]. 2019 Dec [cited 2020 May 20]. Available from: https://doi.org/10.1007/s12108-019-09429-w.

15. Botelho A, Ricupero B, Brasil A. Cosmopolitism and localism in the brazilian social sciences. Can Rev Sociol. 2017;54(2):216-6. 
16. Bastos, ER, Botelho A. Horizontes das Ciências Sociais: Pensamento Social Brasileiro, in C. B. Martins; H. H. T. de Souza Martins (orgs.), Horizontes das Ciências Sociais no Brasil. São Paulo, Anpocs, vol. 1, 2010, p. 475-496.

17. Schwarcz LM, Botelho A. Agenda brasileira. São Paulo: Companhia das Letras; 2011. 393 p.

18. Schwarcz LM, Botelho A. Um enigma chamado Brasil: 29 intérpretes e um país. São Paulo: Companhia das Letras; 2009. 287 p.

19. Brasil Jr A, Jackson LC, Paiva M. O pequeno grande mundo do pensamento social no Brasil. BIB Rev Bras Inf Biblio Ci Soc. 2020;(91):1-38.

20. Brasil Jr A, Carvalho L. Biblioteca Virtual do Pensamento Social: conhecimento, democratização e reflexividade das interpretações do Brasil. Parc Estrat 2017 jul.-dez.;22(45):143-154.

21. Josiowicz A, Brasil Jr A. Pensamento social e pesquisa informacional: o caso da Biblioteca Virtual do Pensamento Social (BVPS). Rev Bras Soc [Internet]. 2019 ago. [citado em 2020 maio 11];7(16). Disponível em: http://www.sbsociologia.com.br/rbsociologia/index.php/rbs/article/view/459.

22. Mena-Chalco J, Cesar Junior R. ScriptLattes: an open-source knowledge extraction system from the Lattes platform. J Braz Comp Soc. 2009 Dec;15(4):31-9.

23. Schwarcz LM, Botelho A. Simpósio: cinco questões sobre o pensamento social brasileiro. Lua Nova. 2011;(82):139-59.

24. Botelho A. Passado e futuro das interpretações do país. Tempo Soc. 2010;22(1):44-66.

25. Grácio MCC. Acoplamento bibliográfico e análise de cocitação: revisão teórico-conceitual. Enc Bibli: R Eletr Bibliotecon Ci Inf [Internet]. 2016 set. [citado em 2020 ago. 24];21(47):82-99.

26. Blondel VD, Guillaume J-L, Lambiotte R, Lefebvre E. Fast unfolding of communities in large networks. J Stat Mech. 2008 Oct; 2008(10):P10008.

27. van Eck NJ, Waltman L. Software survey: VOSviewer, a computer program for bibliometric mapping. Scientometrics [Internet]. 2010 Oct [cited 2020 Aug 24];84(2):523-38. Available from: https://link. springer.com/article/10.1007/s11192-009-0146-3.

28. Bastian M, Heymann S, Jacomy M. Gephi: an open source software for exploring and manipulating networks [Internet]. In: Proceedings of the 3rd Int'l AAAI Conference on Weblogs and Social Media; 2009 May 17-20; California, United States. San Jose: AAAI Press; 2009 [cited 2020 Aug 24]. Available from: https://gephi.org/publications/gephi-bastian-feb09.pdf.

29. Lynch CEC. Cartografia do pensamento político brasileiro: conceito, história, abordagens. Rev Bras Ciên Polí. 2016 abr.;(19):75-119.

30. Martins CB, Lessa R. Horizontes das ciências sociais. Ciência Política [Internet]. São Paulo: Anpocs, Coedição com o Instituto Ciência Hoje, Editora Barcarolla e Discurso Editorial; 2010 [citado em 2020 maio 25]. Disponível em: https://www.anpocs.com/index.php/publicacoes-sp-2056165036/livros/1051horizontes-das-ciencias-sociais-ciencia-politica.

31. Botelho A. Political sociology: state-society relations: Curr Sociol [Internet]. 2014 May [cited 2020 May 25];62(6):868-85. Available from: https://journals.sagepub.com/doi/10.1177/0011392114533213.

32. Oliveira LL. Interpretações sobre o Brasil. In: Miceli S, organizador. O que ler na ciência social brasileira (1970-1995). São Paulo: Sumaré/Anpocs; 1999. p. 147-81.

33. Brandão GM. Linhagens do pensamento político brasileiro. São Paulo: Hucitec; 2007. 220 p.

34. Moretti F. The slaughterhouse of literature. Mod Lang Quart. 2000 Mar;61(1):207-27.

35. Carley K. Coding choices for textual analysis: a comparison of content analysis and map analysis. Sociol Methodol. 1993;23:75-126.

36. Maia JME. Ao sul da teoria: a atualidade teórica do pensamento social brasileiro. Soc Est. 2011 ago.;26(2):71-94.

37. Brasil Jr A. Passagens para a teoria sociológica: Florestan Fernandes e Gino Germani. São Paulo: Hucitec; 2013. 304 p.

38. Botelho A. O Brasil e os dias: estado-nação, modernismo e rotina intelectual. Santa Catarina: EDUSC; 2005. $260 \mathrm{p}$. 
39. Pinheiro D. Jogo de damas: trajetórias de mulheres nas ciências sociais paulistas (1934-1969). Cad Pagu. 2016 abr.;(46):165-96.

40. Pontes H, Cesar RDN, Pontes H, Cesar RDN. Da orla à sala de jantar: gênero e domesticidade na bossa nova e na tropicália. Novos Estud Cebrap. 2019 dez.;38(3):667-88.

41. Daflon VT, Campos LR. Gênero e conhecimento: um diálogo entre o pensamento de Flora Tristan e Harriet Martineau. Estud Históricos. 2020 maio;33(70):424-43.

42. Cobo MJ, López-Herrera AG, Herrera-Viedma E, Herrera F. An approach for detecting, quantifying, and visualizing the evolution of a research field: a practical application to the Fuzzy Sets Theory field. J Informetr. 2011 Jan;5(1):146-66.

43. Aria M, Cuccurullo C. bibliometrix: An R-tool for comprehensive science mapping analysis. J Informetr. 2017 Nov;11(4):959-75.

44. Kallinikos J, Hasselbladh H, Marton A. Governing social practice. Theor Soc. 2013 July;42(4):395-421.

45. Botelho A, Brasil Jr. A, Hoelz M. Tão longe, tão perto: sociologia \& antropologia no limiar de uma década. Sociol Antropol. 2019 dez.;9(3):717-39.

46. Luhmann N. Theory of society. Vol. 2. California: Stanford University Press; 2013. 471 p. 